\title{
Lexis
}

Journal in English Lexicology

16 | 2020

Diachronic Lexical Semantics

\section{When Proper Names Become Verbs: A Semantic Perspective}

\section{Aurélie Héois}

\section{Q OpenEdition \\ 1 Journals}

\section{Electronic version}

URL: http://journals.openedition.org/lexis/4681

DOI: 10.4000/lexis.4681

ISSN: 1951-6215

\section{Publisher}

Université Jean Moulin - Lyon 3

\section{Electronic reference}

Aurélie Héois, "When Proper Names Become Verbs: A Semantic Perspective", Lexis [Online], 16 | 2020, Online since 17 December 2020, connection on 21 January 2021. URL: http:// journals.openedition.org/lexis/4681 ; DOI: https://doi.org/10.4000/lexis.4681

This text was automatically generated on 21 January 2021.

\section{(c) (i) (9)}

Lexis is licensed under a Creative Commons Attribution-NonCommercial-NoDerivatives 4.0 International License. 


\title{
When Proper Names Become Verbs: A Semantic Perspective
}

\author{
Aurélie Héois
}

\section{Introduction}

1 In "When nouns surface as verbs", Clark \& Clark [1979] proposed a semantic analysis of denominal converted verbs, mostly based on Gricean pragmatics, including the innovative use of proper nouns as verbs. Their main concern is to understand why such innovations - which are used in everyday language - are easily understood by the listener in the interaction. For them, this understanding, and hence this linguistic usage, is made possible thanks to a cooperative principle between the participants of an interaction:

For Sam to tell Helen My sister Houdini'd her way out of the locked closet, he must believe that they mutually know that Houdini was an escape artist. Mutual knowledge is used here [...] to mean that Sam and Helen each knows this particular fact about Houdini, each knows that the other knows the fact, each knows that the other knows that the other knows the fact, and so on. If Sam believed that Helen didn't know about Houdini's escape artistry [...], he couldn't have used Houdini cooperatively on that occasion with the sense 'escape by trickery'. [Clark \& Clark 1979: 784]

Based on diachronic data extracted from the Oxford English Dictionary online (from now on $O E D$ ), the present article argues that the pragmatic component of meaning, based on a cooperative principle, is not the only semantic component at play in the building of the meaning of denominal verbs. It operates within a semantic frame determined by the type of the proper name etymon and regular semantic patterns involving metonymy.

3 This article focuses on denominal verbs originating from proper names through a diachronic lens. Proper names differ from common nouns in the fact that they prototypically refer to a unique referent - in place and in time. Syntactically, they usually occur without an article and only allow the plural in very specific cases. The 
central question about proper names used as verbs is related to their meanings. If we take for instance a verb derived from the name of a person, its potential meaning is very wide - relating to that person's habits or personality features or even events they were involved in. The precise meaning of the verb may be determined, as Clark \& Clark [1979] state, by a cooperative principle. However, I argue that even though the context has an impact on the meaning of the output, the derivation of proper names as verbs follows a regular semantic pattern which serves as a basis to its interpretation as a verb in context.

4 The first section (i) defines what a proper name is by taking two opposing semantic trends into account, the 'meaningful' and 'meaningless' theses; (ii) presents the semantics of derivation, with a focus on conversion and -ize suffixation; and (iii) defines what metonymy is from a cognitive perspective and its role in derivation processes. The second section deals with the methodology which made the collection of the data possible and presents the methodological choices for modelling these data for analysis. The third section provides the results and analysis of the data and considers both the evolving and the stable components of verbs originating from proper names. Finally, the fourth section offers a preliminary predictive model based on the available data.

\section{Theoretical background}

\subsection{Proper names}

5 There are many linguistic theories on proper names (from now on PN), some of which take their roots in other disciplines, such as philosophy. The purpose of this article is not to present a description of the wide varieties of theories that exist on PNs; however, as proper names are the basis of this study, some major theoretical trends as well as terminology will be presented in this first section.

6 First of all, the terminological choice of writing about proper names and not proper nouns needs to be clarified. According to Huddleston \& Payne [2002: 515-516], "[p]roper nouns [...] are word-level units belonging to the category noun" while "proper names are expressions which have been conventionally adopted as the name of a particular entity". As a result, these authors will consider Achilles to be a proper noun and Herod the Great to be a proper name containing a proper noun. However, some authors, such as Gary-Prieur [2016], consider Herod the Great to be a compound. According to her, the choice between the two expressions lies in the importance given respectively to the PN as a grammatical entity, or to its referential function (Gary-Prieur [2016: 50]). Moreover, she adds that the main trend in English-written research is the use of the expression proper name. As it has a wider scope, and as the OED uses it in its etymology section, proper name will be the chosen terminology in this article. Moreover, as the present study is interested in verbal semantics, what matters the most is not so much to consider proper names as grammatical units but rather to understand their roles in the semantics of denominal verbs.

7 Discussing the semantics of PNs, Nyström [2016: 40] distinguishes between two main opposite theses: the 'meaninglessness thesis', represented by John Stuart Mill [1882], Saul Kripke [1972] and Keith Donnellan [1972, 1974] among others; and the 'maximum meaningfulness thesis' developed by Otto Jespersen [1924] and Jerry Kuryłowicz [1980], among others. Gary-Prieur's approach is closer to the second thesis as she states that 
the meaning of a proper name has two components: its instructional meaning and its content (Gary-Prieur [2016: 54]). The meaning of a PN is instructional as it is used in an utterance to designate a referent, this component corresponds to the PN naming function. Its content, on the other hand, allows a PN to intrinsically convey some of its characteristics. The difference between these two components is illustrated in the examples below [The Guardian 2020].

(1) Joe Biden has defeated Donald Trump.

(2) The next Donald Trump could be much worse.

In these two examples, the understanding of the utterance relies on the knowledge of who Donald Trump refers to in the real world; its instructional meaning. Yet, shared knowledge of some of the PN characteristics is necessary to understand (2), its content. In (2), this content includes for instance $<$ Donald Trump is the president of the United States>, <Donald Trump is a Republican>, <Donald Trump's presidency has been a disaster in terms of health management, civil rights, etc.>. As a result, shared knowledge is key, as Vaxelaire [2016: 67] points out: “le [nom propre] n'est pas un signe linguistique, seulement une étiquette, vide de sens lorsque le référent est inconnu, et qui prend du poids sémantique plus on en apprend sur ce référent"

The opposition between meaningful and meaningless approaches to PNs is well illustrated by comparing Clark \& Clark [1979] and Štekauer's [1997] respective approaches to the conversion of nouns into verbs. The former research builds its analysis on the assumption that PNs "have reference but no sense" [Clark \& Clark 1979: 783-784]. The authors claim that the meaning of denominal verbs based on PNs depends on the context and on the cooperation between the speaker and the listener. The 'meaninglessness' assumption is the foundation of their differentiation between verbs derived from proper names and verbs based on common nouns. On the other hand, Štekauer [1997] argues that their argument is flawed for two reasons: first, "[t]he existence of converted proper names [...] is the best evidence of the existence of a meaning of proper names"; and secondly, "[o]ur knowledge of a language is always conditioned by the knowledge of 'facts"' [Štekauer 1997:31]. In other words, the difference between verbs based on proper names and verbs based on common nouns does not rest upon the meaningful / meaningless dichotomy. He proposes that the meaning of verbs based on common nouns is the result of the selection of general features of the noun, while the meaning of verbs based on PNs is the result of the selection of idiosyncracies of the PN [Štekauer 1997: 28].

In this article, following Gary-Prieur [2016] and Štekauer [1997], I consider proper names as both linguistic and cultural items whose purpose is to refer to a unique referent, and which convey a meaning that refers to some idiosyncratic characteristics of the referent. However, in contrast to both authors, I do not restrict my study to anthroponyms and toponyms, but I pragmatically follow the OED on what it considers a PN. Later, in the light of the analysis of the data, I return to this matter and to the potential exclusion of some units.

\subsection{The semantics of verbal derivation}

11 Dixon [2008:32-33] lists three verbalization processes in English: conversion, suffixation (-ify, -ize, -ate, -en) and prefixation (en-, be-). However, he notes that only 
conversion and some cases of suffixation (-ify, -ize) are productive in contemporary English. From a diachronic perspective, Early Modern English (EME) counts six verbderiving suffixes: three native (-en, -er, -le) and three non-native ones (-ate, -ify, -ize) (Nevalainen [1999: 406]). Nevalainen [1999: 406] points out that the native suffixes -er and -le usually express reiterative senses while -en is mostly deadjectival. As a result, these suffixes are not expected to be in the present study. According to Nevalainen [1999: 407], the most productive of the borrowed suffixes is -ize. Conversion is the "third-most frequent word-formation process" of the period [Nevalainen 1999: 425], the denominal verbal type being one of the most common in the EME lexicon (Nevalainen [1999: 426]). The present study tends to confirm this trend as the data under scrutiny mainly include conversion and -ize suffixation ${ }^{2}$. From here, I focus on the semantics of conversion and suffixation with no further inquiry into the morphology of the derived verbs, as it is outside the scope of this article.

When considering conversion as a type of derivation, it is relevant to define the semantic relationship that exists between the base and the derived item. In his semantic analysis of denominal verbal conversion in English, Tournier [2007: 185-189] defines four major semantic relationships and four minor ones, according to their frequency. Moreover, he states, along with other researchers such as Plag [1999: 231], that on top of these eight relationships, conversion can imply any kind of semantic relationship. Tournier's typology is summarized in Table 1 with respect to the frequency hierarchy he proposes. More details about the categories which are relevant for this study are given in section 2.2.2.

Table 1. Tournier's typology of semantic relationships in denominal verbal conversion ${ }^{3}$

\begin{tabular}{|l|l|l|}
\hline Relationship type N/V & Hypernym & Typical example \\
\hline Creation & MAKE & tunnel \\
\hline Movement & MOVE & plaster, pocket, scalp \\
\hline Instrument & USE & hammer \\
\hline Behaviour & BEHAVE & ape, treasure \\
\hline *Appropriation & GET & fish \\
\hline *Affectation & *AFFECT & pity, rage, surprise \\
\hline *Location-related occupation & *DO & garden \\
\hline *Time-related occupation & *SPEND & summer, holiday \\
\hline
\end{tabular}

13 Suffixation can also be presented through the lens of its semantic relationship to the stem it is attached to. According to Lieber [2004: 77], "it has been noted [...] that the two affixes [-ify and -ize] show a wide range of polysemy, and not surprisingly, very much the same range of polysemy". These two verb-forming suffixes encompass multiple meanings, similarly to - but not to the same extent as - conversion. Table 2 presents 
Lieber's typology of the various semantic relationships between these two suffixes and their stems [2004: 77]:

Table 2. Lieber's typology of semantic relationships in verb-forming suffixes -ize and -ify

\begin{tabular}{|l|l|l|l|}
\hline Type of relationship & Gloss & -ize & -ify \\
\hline Causative & \multirow{2}{*}{ “make x" } & standardize & purify \\
\cline { 3 - 5 } & "cause to become x" & unionize & yuppify \\
\hline Resultative & “make x go to/in/on something” & apologize & glorify \\
\hline Similative & "do/act/make in the manner of or like x" & despotize & \\
\hline Locative & "make something go to/in/on x" & hospitalize & Syllabify \\
\hline Performative & “do x" & theorize & speechify \\
\hline Inchoative & “become x" & oxidize & acidify \\
\hline
\end{tabular}

14 As mentioned above, the semantics of conversion and suffixation can overlap: the 'similative' meaning, in its "act like x" meaning can be considered the equivalent of the 'behaviour' relationship in the case of conversion. Plag [2003:231] confirms this overlap when he states that "conversion is the most general case in that the meanings of the derivatives with overt suffixes are a subset of the possible meanings of converted verbs".

15 To summarize, apart from their apparent morphological differences, conversion and suffixation share a polysemous character and overlapping semantics, which will be crucial for the study of the semantics of verbs originating from PNs. Even though the tables above describe the semantic relationships between derived verbs and their etymons, it does not mean that the word-formation processes in themselves carry the full semantic content of the relationship. Indeed, the data suggest that metonymic processes are at the heart of denominal verbal derivation.

\subsection{Metonymy}

16 The study of metonymy takes its roots in the classical rhetorical tradition in which it was considered one of the major figures of speech [Panther \& Thornburg 2007: 237]. It was then defined as a "stand for relation in which the name of one thing (henceforth, the source or vehicle) is used to refer to another thing (henceforth, the target) with which it is associated or to which it is contiguous" [Panther \& Thornburg 2007: 237]. More recently, metonymy took a more significant part in linguistic research, especially within the framework of cognitive linguistics. In the present study, metonymy is understood as defined by Kövecses \& Radden [1998: 39]:

Metonymy is a cognitive process in which one conceptual entity, the vehicle, provides mental access to another conceptual entity, the target, within the same domain, or ICM. 
The major similarity between this definition of metonymy and the traditional one can be summarized in the notion of contiguity, in that metonymy happens "within the same domain, or ICM". Kövecses \& Radden's definition, however, moves away from the traditional one on two main aspects: metonymy is not a matter of language, but a cognitive process which impacts language; and metonymy cannot be reduced to a 'stand for' relation between two entities.

The notion of domain, or ICM, is essential in cognitive linguistics, and more specifically in the theory of metonymy. The notion of ICM, for idealized cognitive model, was developed in Lakoff [1987] and can be defined as a "relatively stable mental representation that represent [s] theories about the world" [Evans \& Green 2006: 270]. The 'action' ICM is of interest to the study of verbs originating from PNs as it includes any type of process which can be defined as an action, as well as participants related to that action. For example, the concept of the object HAMMER can be defined within an event involving at least a person holding the hammer, the instrument itself, the action of hammering, and the object being hammered. All these elements, which can be denoted by different parts of speech and lexically unrelated words, are included within the same action ICM. As a result, a metonymic process can happen between the INSTRUMENT and the ACTION, leading to the verb hammer involving the metonymy INSTRUMENT FOR ACTION, which is a type of concept metonymy ${ }^{4}$.

In their description of metonymies within the action ICM, Kövecses \& Radden [1998: 54-55] only use examples of conversions, drawing a clear link between the two processes. The potential link between metonymy and form-changing word-formation processes, such as suffixation, is set aside as they admit that "it is an open question to what extent such morphologically derived forms are still to be treated as metonymies" [Kövecses \& Radden 1998: 55]. However, later in their article, they dedicate one section to the link between metonymies and denominal verbs and base their presentation on the work of Clark \& Clark [1979], which only focuses on conversion. Their conclusion is as follows:

[A]ll of these metonymies are instances of what we called the action ICM. [...] [T]he action ICM and the metonymic relationships that it defines account for literally thousands of denominal verbs. [...] Because [the metonymic relationships] are deeply entrenched and pervasive, they provide speakers with natural "cognitive links" that enable them to move from one entity (the vehicle) to another (the target) without any effort or even subconsciously. [Kövecses \& Radden 1998: 61]

In this quote, the link between conversion and metonymy is officially established. However, the general nature of these concluding remarks suggests that, considering the entrenchment of the "cognitive links", they could apply to the interpretation (and hence the construction) of the meaning of all denominal verbs, regardless of their morphology. The interaction between metonymy and word-formation processes has been observed in many instances. There are still discussions, however, about the exact nature of this interaction. Brdar \& Brdar-Szabò [2013] argue that most metonymies are lexical in nature and either operate on the input or on the output of word-formation processes but rarely at the same time. Janda [2011], on the other hand, argues the opposite and states that there is a "systematic presence of metonymies in wordformation" [Janda 2011: 359] and that a continuum exists between "lexical metonymies and word-formational metonymies" [Janda 2011: 388]. 
The analysis and modelling which were carried out for the present study suggest that some metonymies operate outside word-formation processes, mostly leading to semantic shifts; however, the chronological separation of metonymy and suffixation at the level of verbal derivation leads to more issues than their treatment in simultaneity. The comparison of two competitive forms, such as Pasteur and pasteurize, which both mean "to subject (milk, wine, food, etc.) to pasteurization" ${ }^{5}$ 'pasteurize, v.' 2005] ${ }^{6}$, illustrates the need to propose a unified analysis for converted and suffixed forms. Discussion on the morphology of verbs originating from PNs is outside the scope of this article, however, considering the entrenchment of cognitive processes such as metonymy, as underlined by Kövecses \& Radden [1998], analysing the two forms in terms of metonymy happening alongside conversion and suffixation respectively is not far-fetched. Despite the lack of general agreement on this issue, this study relies on the assumption that metonymic processes can not only occur in cases of conversion but also in other cases of derivation, such as suffixation?

\section{Methodology}

\subsection{Data set building}

The present study is based on a set of data made of 225 verbs originating from proper names and extracted from the OED. Before presenting the methodology used to extract the list of verbs, I present the reasons for choosing the $O E D$ as a linguistic resource along with the limits inherent to such a choice.

\subsubsection{The Oxford English Dictionary as a linguistic resource}

Generally speaking, lexemes which enter a dictionary are 'institutionalized' units. The concept of institutionalization can be defined as "the integration of a lexical item, with a particular form and meaning, into the existing stock of words as a generally acceptable and current lexeme" [Lipka 1992: 8]. As a rule, words which enter a general language dictionary are considered "acceptable". However, Lipka's definition makes it clear that institutionalized items are not always recorded in dictionaries. Indeed, the notion of acceptability should be understood within a linguistic community. As Lipka [1992: 8] notes, "[i]nstitutionalization [...] depends on different regional, social, 'stylistic' and other varieties of a language", and those varieties are not always recorded in written forms or may not live long enough to be recorded in a dictionary. This fact makes it harder for linguists to study some categories of lexical items, such as neologisms. That is why this study focuses on strictly institutionalized words within a diachronic perspective. In other words, I have only considered lexical items which are, or were at some point, recorded in a dictionary, namely the OED. As a result, the present study does not have the ambition of being fully comprehensive. Indeed, it does not include some verbs which are (or were) not frequent enough to be recorded in the OED, nor does it include lexemes which belong to parts of the English language that are not systematically recorded in general language dictionaries - such as slang for example ${ }^{8}$.

The OED was chosen because of its historical nature. In other words, "[y]ou'll still find present-day meanings in the OED, but you'll also find the history of individual words, and of the language" [OED 2018a]. The OED compiles words and phrases from 1150 to the present. Hence the dictionary is mostly interested in Middle and Modern English. The 
diachronic perspective is limited to what is recorded in the selected dictionary, which itself is limited by the availability, or lack thereof, of data from certain periods of time, as well as the selection process of the OED [Algeo 1998: 61]. Unsurprisingly, there are far more entries from the $16^{\text {th }}$ century onwards than for the period before. This observation can probably be partly explained by the invention and development of printing in Europe.

Because the OED records words and phrases along with their definitions, etymology and quotations, it displays a wealth of information for the linguist to analyse. Moreover, each entry includes the first known attestation for each definition of a lexeme and its date. As a result, it can be hypothesized that this dictionary gives a relatively correct picture of a derived lexeme when it was first coined. It is however possible that some meanings of a lexeme may be put aside for lack of 'currency' or 'frequency' as both are the criteria used by lexicographers to decide whether an entry should be created [OED 2018b]. However, as Algeo [1998: 63] points out, the OED "is not reliable for the earliest dates of use of words, although it is the best record we have".

The data extracted from the OED (see Section 2.1.2. for the methodology) resulted in 225 entries whose first dates of attestation range from 1330 to 2008. However, as more than 200 years separate the most ancient entry (roam) with the next (hackney), this first entry was put aside. Moreover, while Early Modern English is already 'modern' in its word-formation processes, the situation is quite different for Middle English as it can be seen as a transition period, as Nevalainen [1999: 377] indicates:

This classification [of word-formation processes] reflects the important typological change in English from stem-formation in old English to word-formation as we know it today. In the course of the Middle English period invariant free lexemes came to be established as bases for word-formation.

27 As a result, the focus is put on the period from 1575 to 2008 . The whole period is usefully divided following Graddol et al. [2007: 80], Lass [1999: 9] and Romaine [1998: 7] into three parts: $16^{\text {th }}$ and $17^{\text {th }}$ centuries for Early Modern English (EME); $18^{\text {th }}$ century for Modern English (ModE); and $19^{\text {th }}$ century until now for Late Modern English (LME). This last period was arbitrarily divided into two subparts so that all the periods would roughly last a century. As a result, LME1 covers the $19^{\text {th }}$ century, while LME2 covers the $20^{\text {th }}$ century and the beginning of the $21^{\text {st }}$ century.

\subsubsection{Extracting the data}

In order to compile a list of verbs formed from proper names, I used the search tool of the OED and selected the part of speech 'verb'. The original aim was to find verbs whose etymology refers to a proper name. Unfortunately, a direct search through the 'origin' field of each entry was impossible; as a result, I had to search through the entire entries - 'in full text'. Observations made on test entries, allowed me to define three sets of keywords to search 'in full text': "from a proper name", "from proper names" and "proprietary name". The last set was the result of an observation made for verb entries such as Google and Facebook which consider the etymon a proper name while hoover is mentioned as coming from a proprietary name. ${ }^{10}$

29 I also chose to include verbs which indirectly originate from a PN. This means that the OED lists them as originating from another lexeme - mostly a noun or an adjective which itself comes from a PN. Indeed, the comparison of Manchesterize and Birminghamize showed that, from a semantic point of view, there are no differences in 
the relationship between the verb and the PN etymon even though the former is listed as deriving from a common noun, itself originating from a PN. Table 3, with the definitions of the two verbs, illustrates this lack of difference in the verb-PN relationship:

Table 3. Comparison of the definitions of Birminghamize [2016] and Manchesterize [2000]

\begin{tabular}{|l|l|}
\hline $\begin{array}{l}\text { To } \\
\text { Birminghamize }\end{array}$ & $\begin{array}{l}\text { To cause to resemble or follow the example of Birmingham, with regard to its } \\
\text { local government. }\end{array}$ \\
\hline $\begin{array}{l}\text { To } \\
\text { Manchesterize }\end{array}$ & $\begin{array}{l}\text { To make representative or typical of Manchester; to make similar to } \\
\text { Manchester, esp. with regard to industrial practices. }\end{array}$ \\
\hline
\end{tabular}

Indeed, both verbs are transitive, and both directly refer, in their definition, to the PN they come from. Hence, both verbs are relevant to this study.

The issue of directionality also motivated that choice as determining directionality can be challenging and the data available is not always enough to do so with certainty (Valera [2014: 160-161]). As a result, the etymology listed in the OED is not always to be taken for granted.

Unfortunately, there was no systematic method to find verbs which indirectly come from PNs. Consequently, a manual search was put in place in order to compile these verbs: first, an advanced search was carried out with the same keywords as before but for other parts of speech; then, for each selected entry, related 'verb' entries were opened in order to assess if the selected verb was a derivative of the first entry. The main drawback of this method, beyond being manual, consists in only taking into account verbs in neighbouring entries. This explains why very few prefixed verbs were collected. Considering the time-consuming nature of this manual search, only verbs with a second-degree relationship to PNs were included, while keeping in mind that third-degree relationships (or more) could have been relevant as well.

\subsection{Data modelling}

A data set of derived words can be modelled through a variety of features. For lack of space, the morphology of the derived verbs is not considered in the present article. I only focus on verbal semantics and the relationship with the PN etymon from a diachronic perspective. In order to do so, the date of first attestation of each verb was collected along with their first definition ${ }^{11}$ and etymology as listed in the OED. As a result, the present study does not consider the evolution of each verb and the semantic shifts they encountered through their existence.

\subsubsection{Proper name categories}

34 According to Gary-Prieur [2016: 56], no proper classification of PNs exists apart from intuition-based lists. However, such available classifications are still useful as they allow the grouping of the entries into relatively homogenous groups. Each PN etymon was categorized according to a simplified version of what Huguin proposed in a presentation of her PhD thesis (Huguin [2018]). She distinguishes five families, based on 
the nature of the referent: anthroponyms are prototypically the names of specific human beings or animals; toponyms are the names of places whether natural or human-made; phenonyms are the names of natural phenomena; ergonyms are the names of material human-made creations or inventions; and praxonyms are the names of non-material creations or discoveries ${ }^{12}$. The present categorization was based on this classification but with terminological and categorial changes: the type 'person' is the exact equivalent of the anthroponym category; the type 'place' is used in place of toponym but would also include some phenonyms such as stars and planets as they are located entities; finally, the type 'products \& services' includes commercial creations which are either ergonyms or praxonyms. When it comes to discoveries whose name is eponymous to its inventor / discoverer, it was coded in the 'person' type which takes precedence in this study.

Each type of PN was then subcategorized. The 'person' type was first subcategorized between 'fictitious' (Aladdinize), 'generic' (merryandrew) and 'historical' (bogart). The generic subcategory may appear surprising as it seems to contradict the definition of a $\mathrm{PN}$, namely its referring function to a specific individual. However, proper names are not coined out of nowhere but are linked to a name-stock (McClure [2012]). This notion is useful to understand why there is no issue in including generic names, even though they do not fully behave like PNs in their reference.

Place PNs were categorized according to their location - 'Africa' (maffick $\left.{ }^{13}\right)$, 'America' (Canadianize), 'Asia' (Babylonize), 'Europe' (Locarnize), and 'Pacific' (Pearl Harbour). Finally, products \& services PNs (P\&S PN) were divided between products (Blu-Tack) and services (Skype) however blurry the line between the two can be. Whenever possible, the country of the PN was added to the information gathered, for instance 'Italy' for Petrarchize, 'Ancient Greece' for Pindarize, 'UK' for Malthusianize, or 'USA' for Morse.

\subsubsection{Verb/proper name semantic relationship}

As mentioned in Section 1.2., there are two major word-formation processes in the data: suffixation in -ize and conversion. I presented two different typologies of the semantic relationship between a noun and its derived verb (Lieber [2004]; Tournier [2007]). However, in order to analyse the data, it is crucial to choose only one model and thus be able to compare the semantic relationships independently from the verbal morphology. The keyword typology proposed by Tournier was preferred for this study because, as Lieber states, "the semantic range exhibited by converted verbs is larger even than those of -ize verbs" [Lieber 2004: 90]. Apart from the eight most frequent types of semantic relationships, conversion can imply any other kind of relationship (Tournier [2007: 189]), hence some semantic relationships did not fall perfectly into Tournier's eight categories and I added some extra categories ${ }^{14}$ on a comparable model, as summarized in Table 4:

Table 4. Data modelling of the semantic relationship between $\mathrm{V}$ and $\mathrm{PN}^{15}$

\begin{tabular}{|l|l|l|}
\hline $\begin{array}{l}\text { Semantic } \\
\text { relationship }\end{array}$ & $\begin{array}{l}\text { Relationship } \\
\text { gloss }\end{array}$ & Examples \\
\hline
\end{tabular}




\begin{tabular}{|c|c|c|}
\hline BEHAVE/APE & $\begin{array}{l}\text { Behave like / act } \\
\text { as PN }\end{array}$ & $\begin{array}{l}\text { Bobbitt: "To cut off the penis of (a man, esp. a husband or } \\
\text { lover), typically as an act of revenge for perceived sexual } \\
\text { grievances" [2018] }\end{array}$ \\
\hline $\begin{array}{l}\text { *BEHAVE/ } \\
\text { INVENTION }\end{array}$ & $\begin{array}{l}\text { Behave like the } \\
\text { invention of PN }\end{array}$ & $\begin{array}{l}\text { zeppelin: "To move in a manner reminiscent of a Zeppelin" } \\
\text { [2014] }\end{array}$ \\
\hline *BEHAVE+PITY & $\begin{array}{l}\text { Behave as if } \\
\text { affected by PN('s } \\
\text { ideas) }\end{array}$ & $\begin{array}{l}\text { Mendelize: "To behave or be inherited in accordance with } \\
\text { Mendelian principles" [2001] }\end{array}$ \\
\hline $\begin{array}{l}\text { BEHAVE/ } \\
\text { TREASURE }\end{array}$ & $\begin{array}{l}\text { Behave as } \\
\text { towards PN }\end{array}$ & $\begin{array}{l}\text { boycott: "Of tenants in Ireland: to isolate and ostracize (a } \\
\text { landlord or land agent, or anyone not participating in such } \\
\text { action) socially and commercially, by withholding labour, } \\
\text { the supply of food, custom, etc., in order to protest at the } \\
\text { eviction of tenants, secure a reduction in rents, etc." [2008] }\end{array}$ \\
\hline GARDEN & $\begin{array}{l}\text { Act in a manner } \\
\text { typical in PN }\end{array}$ & Newgate: "To imprison in Newgate" [2003] \\
\hline MAKE & $\begin{array}{l}\text { Make, create a } \\
\text { PN }\end{array}$ & Penguin: "To publish as a Penguin book" [2005] \\
\hline *MAKE LIKE & Make like PN & $\begin{array}{l}\text { Manhattanize: "To make similar in character or appearance } \\
\text { to Manhattan or its inhabitants" [2000] }\end{array}$ \\
\hline *MAKE+BEHAVE & $\begin{array}{l}\text { Make in the } \\
\text { manner of } / \\
\text { according to PN }\end{array}$ & $\begin{array}{l}\text { macadamize: "Originally: to make or repair (a road) according } \\
\text { to McAdam's method" [2000] }\end{array}$ \\
\hline *MAKE+GARDEN & $\begin{array}{ll}\text { Make in a } \\
\text { manner typical } \\
\text { in PN }\end{array}$ & morocco: “ To make into morocco (leather)” [2002] \\
\hline \multirow{2}{*}{$\begin{array}{l}\text { *OUT } \\
\text { ANALYSIS }\end{array}$} & $\begin{array}{l}\text { Indirect } \\
\text { opaque } \\
\text { relationship }\end{array}$ & $\begin{array}{l}\text { Great-Scott: “To exclaim 'Great Scott!' (at), express great } \\
\text { surprise (at)” [2013] }\end{array}$ \\
\hline & $\begin{array}{l}\text { Unknown } \\
\text { referent }^{16}\end{array}$ & jack: "To raise or hoist by means of a jack"17 [2018] \\
\hline PLASTER & $\begin{array}{l}\text { Put PN on / give } \\
\text { PN }\end{array}$ & artex: "To paint or decorate with Artex paint" [2008] \\
\hline $\begin{array}{l}\text { *PLASTER/ } \\
\text { INVENTION }\end{array}$ & $\begin{array}{l}\text { To put the } \\
\text { invention of } \mathrm{PN} \\
\text { on }\end{array}$ & Pitmanize: "To fill (a book) with Pitman shorthand" [2006] \\
\hline USE & Use PN & $\begin{array}{l}\text { Facebook: "To contact (a person) using the social networking } \\
\text { service Facebook" [2018] }\end{array}$ \\
\hline
\end{tabular}




\begin{tabular}{|l|l|l|}
\hline *USE+GARDEN & $\begin{array}{l}\text { Use in a manner } \\
\text { typical in PN }\end{array}$ & $\begin{array}{l}\text { hackney: “To use (a horse) as a hackney, for general-purpose } \\
\text { riding” [2016] }\end{array}$ \\
\hline $\begin{array}{l}\text { *USE/ } \\
\text { INVENTION }\end{array}$ & $\begin{array}{l}\text { Use the } \\
\text { invention of PN }\end{array}$ & $\begin{array}{l}\text { prusik: "To climb with the aid of prusik loops or similar } \\
\text { devices" [2007] }\end{array}$ \\
\hline
\end{tabular}

This table shows that five of Tournier's eight semantic relationships are present in the data. According to Tournier [2007: 185-189], BEHAVE, MAKE and USE are part of the four most frequent semantic relationships in denominal verbal conversions, PLASTER is a subtype of the fourth major relationship, i.e. MOVE. GARDEN on the other hand is less frequent and is the only type of what Tournier calls minor semantic relationships, which is present as such in the data. In order to include the whole data, I created eight categories on a similar model to Tournier's. They are more complex than the major semantic relationships, which is unsurprising as conversion, and more generally derivation, can include complex and varied relationships between the derived lexeme and its etymon, as Tournier [2007:189] points out: "En fait, on peut pratiquement rencontrer toutes sortes de relations, dont certaines sont complexes (mais se rapprochent parfois de l'un des types majeurs)" ${ }^{18}$. The creation of these categories is based on two principles: the observation of the data, and Tournier's typology.

The USE/INVENTION relationship for example comes from the observation that some verbs show a clear USE meaning while the paraphrase "to use PN" cannot be applied, as illustrated in (3) ['Mauser, n.' 2001; 'Mauser, v.' 2001]:

\begin{tabular}{|l|l|}
\hline (3) & Mauser $v .=$ to shoot with a Mauser rifle \\
\hline & $<$ Peter Paul von Mauser and his brother, German firearms designers \\
\hline & a. * to use Mauser \\
\hline & b. to use the invention of Mauser \\
\hline
\end{tabular}

40 (3a) is impossible because the PN Mauser refers to a person and cannot be a paraphrase of the definition. This impossibility is due to the methodological choice of directly linking the verb to its PN etymon through this semantic relationship. However, the next section will take into account the similarity between the USE/INVENTION and the USE verbs.

41 As Table 4 shows, some of the new categories include the "+" sign. All these cases are a combination of Tournier's categories in order to create a new relationship. PITY, which is one of the minor relationships presented by Tournier and which could be paraphrased as "to affect / be affected by X" [Tournier 2007: 188], is not present in its simple form in the data but is used in a compound relationship with BEHAVE. Finally, the MAKE LIKE relationship is based on the MAKE relationship and on the observation that in most cases of creation-events, the result is not the original creation but only something similar. If we compare joke (Tournier [2007: 185]) with Manhattanize, we can notice that the MAKE paraphrase "to make X" applies to joke but is more problematic for Manhattanize. The specific nature of PNs may explain this difference: Manhattan is a 
specific island situated in a specific location and looks a certain way, as a result it is impossible to create Manhattan somewhere else, the only option is to create something resembling Manhattan in some respects. ${ }^{19}$

\subsubsection{Metonymic processes: rethinking semantic relationships}

As I explained in Section 2.2.2., the categorization of verbs according to their semantic relationships with their etymons does not allow to regroup within the same category verbs which function along the same semantic pattern, as I illustrated in (3) with the USE/INVENTION relationship. In order to account for the similarity between different types of semantic relationships as defined in the previous section, I decided to describe the word-formation processes at work, whether morphological or cognitive. Purely morphological processes such as affixation, conversion, backformation, back-clipping ${ }^{20}$, and compounding were listed for each entry along with cognitive processes such as metaphor and metonymy.

In order to better analyse the data, I divided the word-formation processes into two steps: the first step attempts to describe the processes at play before verbal derivation; the second step deals with the processes happening during verbal derivation. This division does not mean that each step will show a unique process. It is mostly visible in step 1 as it often includes several processes either simultaneously or successively.

The entries Americanize ("To make American; to absorb or assimilate into American culture or society" ['Americanize, v.' 2008]), Manhattanize (definition in Section 2.2.2.) and Pearl Harbour ("To attack suddenly and without warning" ['Pearl Harbour, v.' 2005]) are good examples of the step-by-step analysis as they include several (and different) types of word-formation processes:

Table 5. Word-formation analysis of Americanize, Manhattanize, and Pearl Harbour

\begin{tabular}{|c|c|c|c|}
\hline \multirow[t]{2}{*}{ America $_{\mathrm{PN}}$} & $>$ & America- $\mathrm{n}_{\mathrm{A}}$ & $>$ American-ize ${ }_{\mathrm{v}}$ \\
\hline & $\begin{array}{l}\text { PLACE FOR INHABITANTS / } \\
\text { SOCIETY }\end{array}$ & \begin{tabular}{|lll} 
CATEGORY & FOR DEFINING \\
PROPERTY & & \\
\end{tabular} & $\begin{array}{l}\text { PROPERTY FOR RESULT OF } \\
\text { ACTION }\end{array}$ \\
\hline [place] & [person/society] & [property] & [action] \\
\hline Manhattan $_{\mathrm{PN}}$ & & $>$ & Manhattan-ize ${ }_{v}$ \\
\hline & & \begin{tabular}{|lll} 
CATEGORY & FOR & DEFINING \\
PROPERTY & &
\end{tabular} & $\begin{array}{l}\text { PROPERTY FOR RESULT OF } \\
\text { ACTION }\end{array}$ \\
\hline [place] & & [property] & [action] \\
\hline $\begin{array}{l}\text { Pearl } \\
\text { Harbour }_{\mathrm{PN}}\end{array}$ & $>$ & Pearl Harbour ${ }_{N}$ & Pearl Harbour ${ }_{v}$ \\
\hline & & PLACE FOR EVENT & EVENT FOR ACTION \\
\hline
\end{tabular}




\begin{tabular}{|l|l|l|l|}
\hline [place $]$ & {$[$ event $]$} & {$[$ action $]$} \\
\hline Step 1 & & Step 2 \\
\hline
\end{tabular}

The comparison between Americanize and Manhattanize shows for instance that the CATEGORY FOR DEFINING PROPERTY metonymy is not always linked to the existence of an adjectival suffix but is nevertheless necessary as an intermediary step so that the verbal meaning is built.

As a result of the step analysis, it appears that the categories defined in the previous section and based on the direct relationship between the PN and the verb hide both different and similar verbal behaviours. The similarities between the USE and USE/ INVENTION verbs was expected, and, unsurprisingly, they all involve the action metonymy of the type INSTRUMENT FOR ACTION. Some differences and similarities are hence brought to light by the comparison of the action metonymies (step 2) which are listed in Table 6.

Table 6. Action metonymies (step 2)

\begin{tabular}{|c|c|}
\hline Metonymy & Example \\
\hline AGENT FOR ACTION & Poor-Robin: "To play the part of Poor Robin" [2006] \\
\hline EVENT FOR ACTION & Pearl Harbour (Section 2.2.3.) \\
\hline INSTRUMENT FOR ACTION & Mauser (Section 2.2.2.) \\
\hline $\begin{array}{l}\text { INSTRUMENT FOR RESULT OF } \\
\text { ACTION }\end{array}$ & Maxim: "To kill with a Maxim gun" ['Maxim, $\mathrm{v}^{2}$ ' 2001] \\
\hline $\begin{array}{lll}\text { OBJECT } & \text { INVOLVED } & \text { FOR } \\
\text { ACTION } & & \end{array}$ & $\begin{array}{l}\text { Astroturf: "To cover (a sports field or other area) with a layer of } \\
\text { Astroturf" [2012] }\end{array}$ \\
\hline PROCESS FOR ACTION & Pasteur: "To subject (milk, wine, food, etc.) to pasteurization" [2005] \\
\hline $\begin{array}{llll}\text { PROCESS } & \text { FOR RESULT } & \text { OF } \\
\text { ACTION } & & & \end{array}$ & Pitmanize (Section 2.2.2.) \\
\hline PROPERTY FOR ACTION ${ }^{21}$ & $\begin{array}{l}\text { MacGyver: "To construct, fix, or modify (something) in an improvised or } \\
\text { inventive way" [2019] }\end{array}$ \\
\hline $\begin{array}{l}\text { PROPERTY FOR RESULT OF } \\
\text { ACTION }\end{array}$ & Nimrod: "To make into a hunter" [2003] \\
\hline RESULT OBJECT FOR ACTION & Penguin (Section 2.2.2.) \\
\hline
\end{tabular}

The GARDEN category is a good example of both diverging action metonymies and surprising similarity with another category. Indeed, the step analysis of this category shows two different metonymic behaviours as summarized in (4) and (5): 
(4) CATEGORY FOR DEFINING PROPERTY > PROPERTY FOR ACTION 'port, $\mathrm{v}^{5}$ ': "to drink port" [2006]

(5) place for event > event for action

'Locarnize, v.': “To bring about peace (in a region) by negotiation” [2015]

(4) shows the same chain of metonymies as the verbs of the BEHAVE relationship.

Consequently, as the semantic relationship between the PN and the verb does not seem to take these differences and similarities into consideration, a new categorization is needed in order to take the semantic behaviours of the verbs into account. This new categorization is based on the action ICM metonymies and enables to create new categories, which I will refer to as 'semantic families'. Table 7 maps the new semantic families to the previous categories and the related metonymy.

Table 7. Semantic families

\begin{tabular}{|c|c|c|c|}
\hline Semantic family & V/PN semantic relationship & Metonymy (step 2) & Example \\
\hline APE & BEHAVE/APE & AGENT FOR ACTION & Poor-Robin \\
\hline \multirow{5}{*}{ BEHAVE } & BEHAVE/APE & \multirow{5}{*}{ PROPERTY FOR ACTION } & Bobbitt \\
\hline & BEHAVE/TREASURE & & boycott \\
\hline & BEHAVE/INVENTION & & zeppelin \\
\hline & GARDEN & & Newgate \\
\hline & OUT OF ANALYSIS & & Great-Scott \\
\hline GARDEN & GARDEN & EVENT FOR ACTION & Locarnize \\
\hline \multirow{3}{*}{ MAKE } & MAKE & \multirow{3}{*}{ RESULT OBJECT FOR ACTION } & Penguin \\
\hline & MAKE+BEHAVE & & Rumfordize 22 \\
\hline & MAKE+GARDEN & & morocco \\
\hline \multirow{3}{*}{ MAKE LIKE } & MAKE LIKE & \multirow{3}{*}{ PROPERTY FOR RESULT OF ACTION } & Birminghamize \\
\hline & MAKE+BEHAVE & & McDonaldize $e^{23}$ \\
\hline & OUT OF ANALYSIS & & Nestorize $^{24}$ \\
\hline \multirow{3}{*}{ MAKE+BEHAVE } & MAKE+BEHAVE & \multirow{3}{*}{ PROCESS FOR (RESULT OF) ACTION } & pasteurize \\
\hline & BEHAVE+PITY & & Mendelize \\
\hline & PLASTER/INVENTION & & Pitmanize \\
\hline \multirow{2}{*}{ PLASTER } & PLASTER & \multirow{2}{*}{ OBJECT INVOLVED FOR ACTION } & Astroturf \\
\hline & OUT OF ANALYSIS & & Oscar ${ }^{25}$ \\
\hline
\end{tabular}




\begin{tabular}{|c|c|c|c|}
\hline \multirow{4}{*}{ USE } & USE & \multirow{4}{*}{ INSTRUMENT FOR (RESULT OF) ACTION } & Facebook \\
\hline & USE/INVENTION & & Prusik \\
\hline & USE+GARDEN & & hackney \\
\hline & OUT OF ANALYSIS & & Jack \\
\hline
\end{tabular}

In some cases, the action ICM metonymy of step 2 minimally differs from what is considered the main metonymic process at work in each family. For instance, Maxim (see Table 6 for a definition) is part of the USE family even though the action ICM involved is not INSTRUMENT FOR ACTION but INSTRUMENT FOR RESULT OF ACTION. However, the metonymy can be decomposed into two parts which combine at the step 2 level: INSTRUMENT FOR ACTION + CAUSE FOR EFFECT. As a result, the action ICM metonymy remains the same as for the other verbs of the family even though the cognitive processes at work in the semantic creation of the verb are more complex. The situation is the same for the MAKE+BEHAVE family. Yet, the 'result' criterion does not always imply that the CAUSE FOR EFFECT decomposition is relevant, as the comparison of the BEHAVE and MAKE LIKE families shows. Indeed, they share similarly-worded metonymies with only a 'result' difference, but contrary to an instrument or a process, a property cannot be analysed as the necessary cause for an effect. That is why the two families are kept separate.

\section{Results and analysis}

\subsection{An apparent increase over time}

Figure 1 shows the percentage of entries according to the period of time. 
Figure 1. Proper names as verbs $-1575-2008$

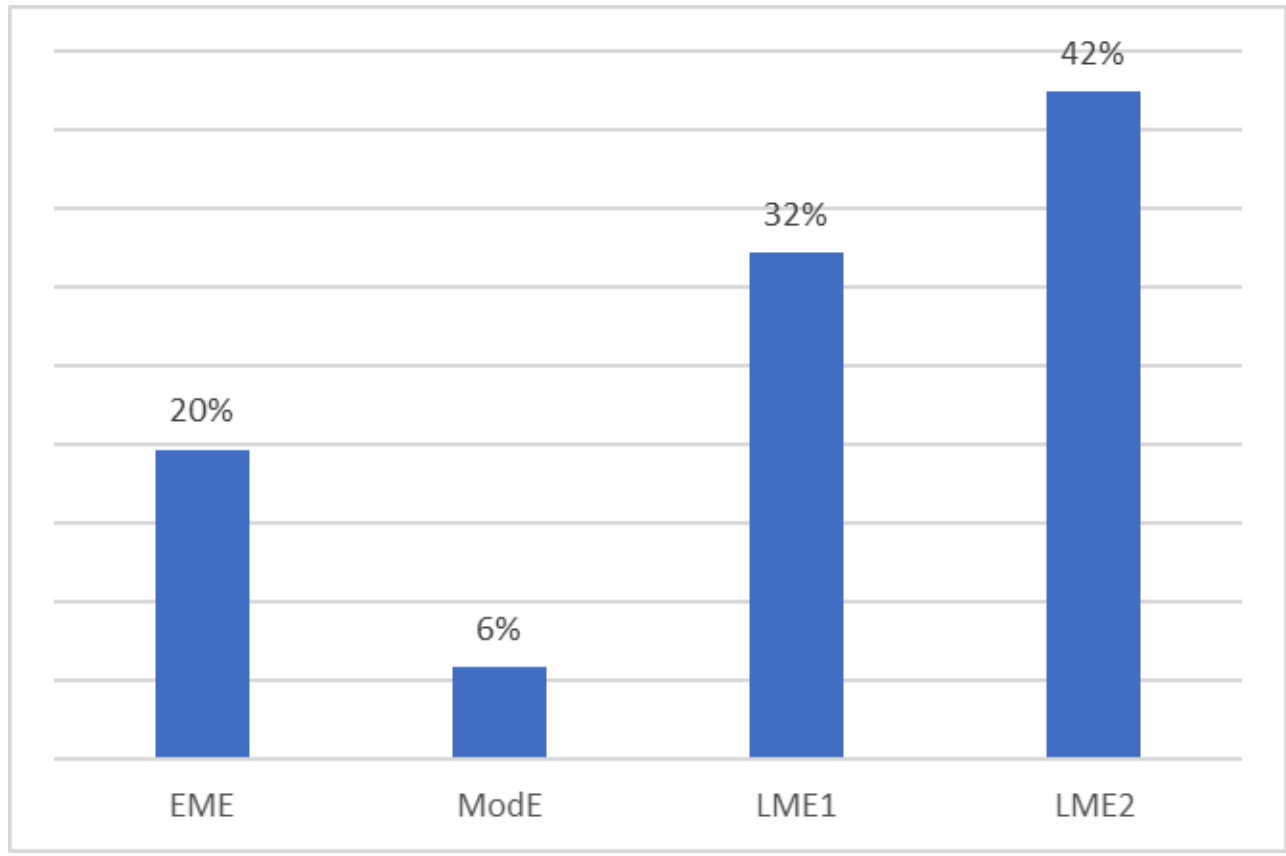

Putting the ModE period aside, there seems to be a continuous increase in the number of verb creations originating from PNs over time. With only $6 \%$ of the data coming from the ModE period, this apparent gap is surprising. While Algeo [1998: 63] points out that the period of LME was likely to be more productive in terms of lexical creation, and Nevalainen [1999:336] states that the ModE period went through a more moderate growth than the EME time, such a discrepancy between the periods may also be linked to a lack of data for that time, or issues with the OED first dates of attestation (Algeo [1998]). As a rule, the data from the ModE period have to be analysed with caution.

Moreover, this distribution hides more subtle realities, as Figure 2 reveals. This graph shows the evolution of verb creations through time according to their PN etymons.

Figure 2. Type of PN used as verbs - 1575-2008

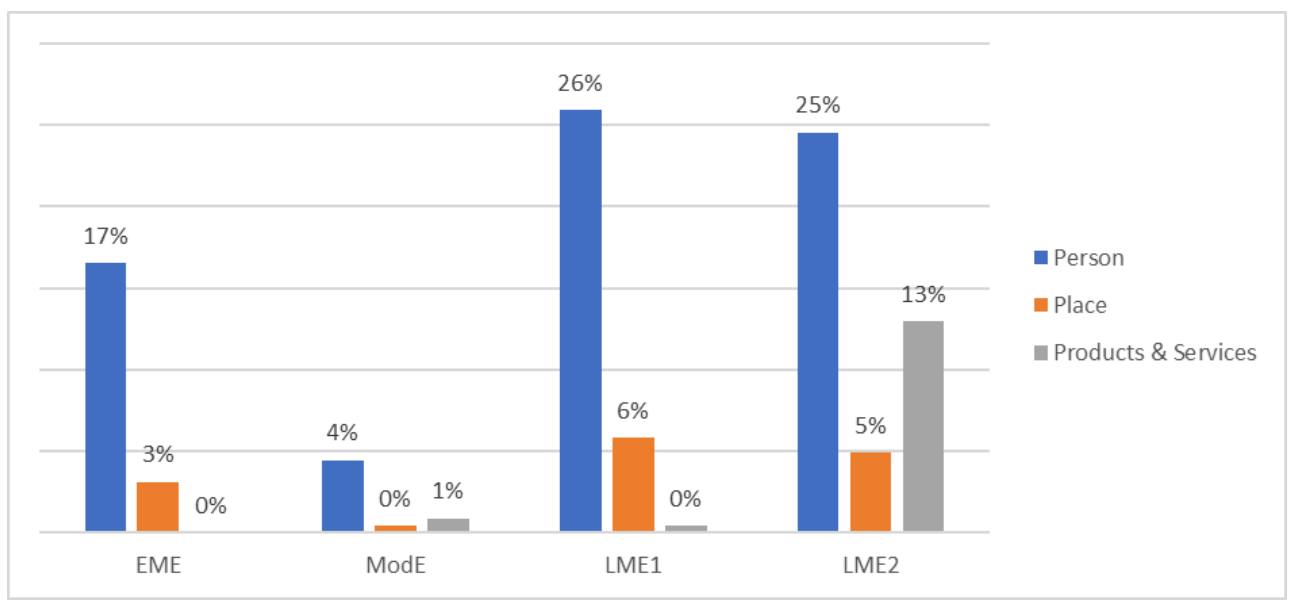

Indeed, while there appears to be an increase during the LME period compared to the ones before, this increase is mostly linked to the appearance of verbs deriving from P\&S PN (see Section 3.3. for discussion). Another striking element is also the relative 
stability of verbs originating from person PNs (blue columns), as well as their overwhelming presence. Figure 2 confirms the increase in the derivation of verbs from PNs through time, but the EME period already shows a high percentage of Person PN verbs (17\%) even when compared to the later period (respectively $26 \%$ and $25 \%$ for LME1 and LME2). Finally, the coinage of verbs from Place PN is quite low in every period, but also quite stable.

\subsection{Proper names as verbs: a reflection of culture and society}

As mentioned in Section 1.1., proper names are both linguistic and cultural products. One aim of compiling verbs from PNs in a diachronic perspective is to obtain a picture however limited - of the time they were coined. Indeed, in order to be used as a verb and institutionalized as such, beyond all the other criteria which apply to any neologism (gap in vocabulary, new reality, etc.), a proper name needs to be sufficiently known within a linguistic community so as to 'stick', and its main properties need to be salient enough so that they can be selected by this community to create a verb. As a result, when we look back at the institutionalization of verbs from PNs, it gives an image of some of the features of the culture and society in which they are used.

The analysis of the country of origin of each PN, for instance, shows the links between English-speaking countries and other countries around the world. Apart from the expected United Kingdom (UK) and United States of America (USA), a large number of different countries (40) are present in the data, most of which appear to have a relatively low influence on English culture(s) as the majority (57\%) have only one entry in the data set. This includes English-speaking countries such as Canada, Australia or Ireland. This observation is probably linked to the methodology of the OED which appears to favour the two main English standards for their sources ${ }^{26}$. It is also possible that the influence of British and American cultures spread more widely around the English-speaking world and, as a result, British or American PNs are more salient to the linguistic communities. Together, the UK and the USA account for more than half of the entries of the present data set.

Other countries which count more than five entries are: France (9), Germany (10), Ancient Greece (11), Italy (5), the Bible (8) and Greek mythology (5). The last two origins may be curious at first sight, but it is quite impossible to pinpoint a specific country for these two themes as the Bible has been translated very often, and Greek mythology has been a literary theme through history, and especially during the Renaissance.

Even though it is not surprising that European countries, Antiquity and Christianism stand out, in order to determine the influence of foreign cultures on the English language and English-speaking societies, more data should be gathered. First, a differentiation between the varieties of English would probably show differences between countries and cultures in PN verb usage. This differentiation is not possible with the OED alone and corpus linguistics would be of help in this case. What this branch of linguistics can also bring is a frequency analysis of these verbs which would deliver a better picture of relative influence.

Apart from the national origin of PNs, thematic origin can also provide a window to the culture and society of the time a verb was coined. As most of the data (47\%) is of the type 'historical', categorizing each PN according to a theme - the domain the PN referent is known for, may give a picture of the themes of interest at a given time. 
Figure 3. Historical PNs through time

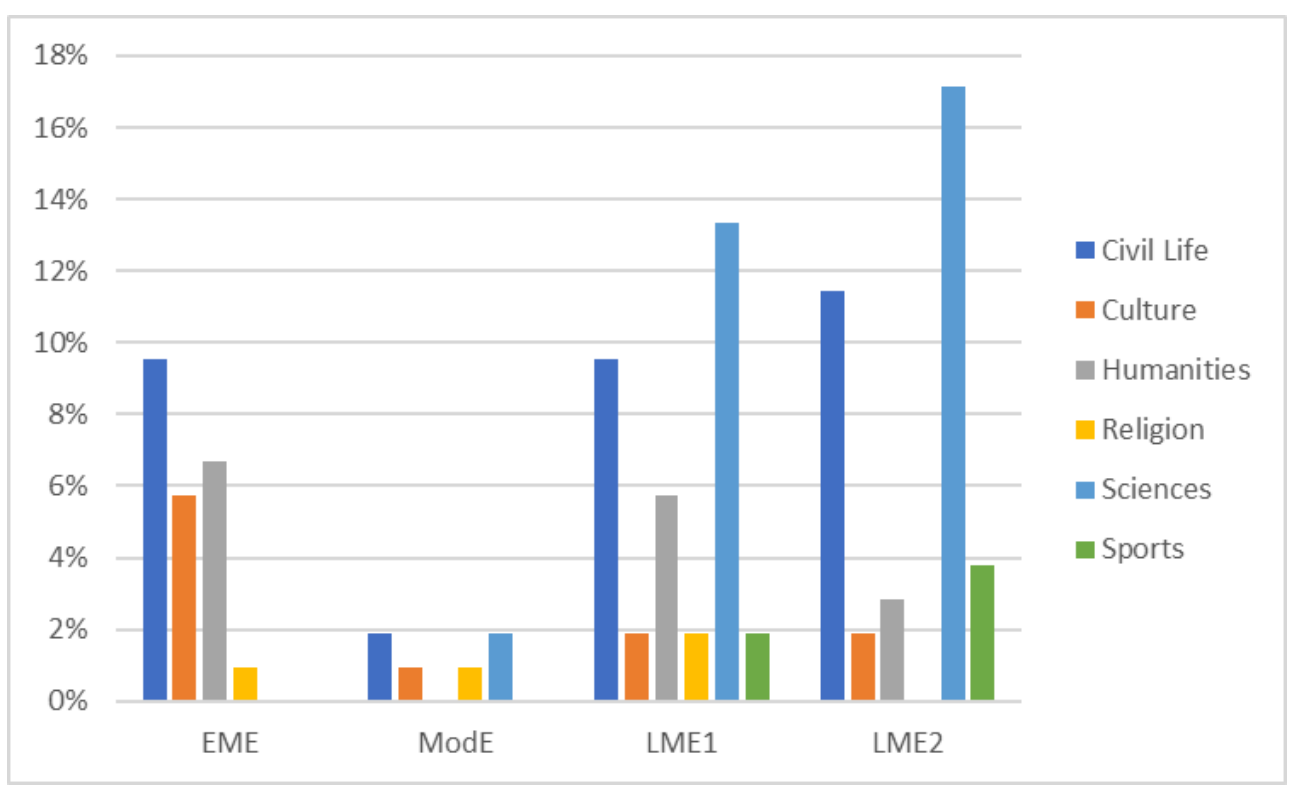

60 Figure 3 suggests that some themes are more salient according to the period. EME appears to favour three main themes, in order of importance: 'Civil life', 'Humanities' and 'Culture'. Once again, the ModE period is put aside as not enough data is included in the study. The LME1 period shows the rise of 'Sciences', while 'Civil life' and 'Humanities' still have a relatively strong hold. Finally, the LME2 period confirms the domains of 'Sciences' and 'Civil life' while the 'Sports' category seems to be on the rise. However, as 105 verbs are part of the 'historical' category, subdividing this category into four periods and each period into six themes leads to an average of 4.3 verbs per theme/period. This small amount of data does not allow for any sociocultural generalization even though Figure 3 tends to support some intuitions. For instance, the sudden appearance of sports-related verbs (green columns) in the $19^{\text {th }}$ century is probably linked to the "consolidation of organized sports" during that century ['sports, n1 (4.a.)' 2008], but the present data should be consolidated so that this hypothesis can be verified.

\subsection{What type of meaning?}

61 In this section, I present the types of verbal meanings according to the modelling of semantic families presented in Section 2.2.3. Figure $4^{27}$ shows clear tendencies linking the type of PN and the semantic behaviour of the verb. 
Figure 4. Semantic families according to type of PN

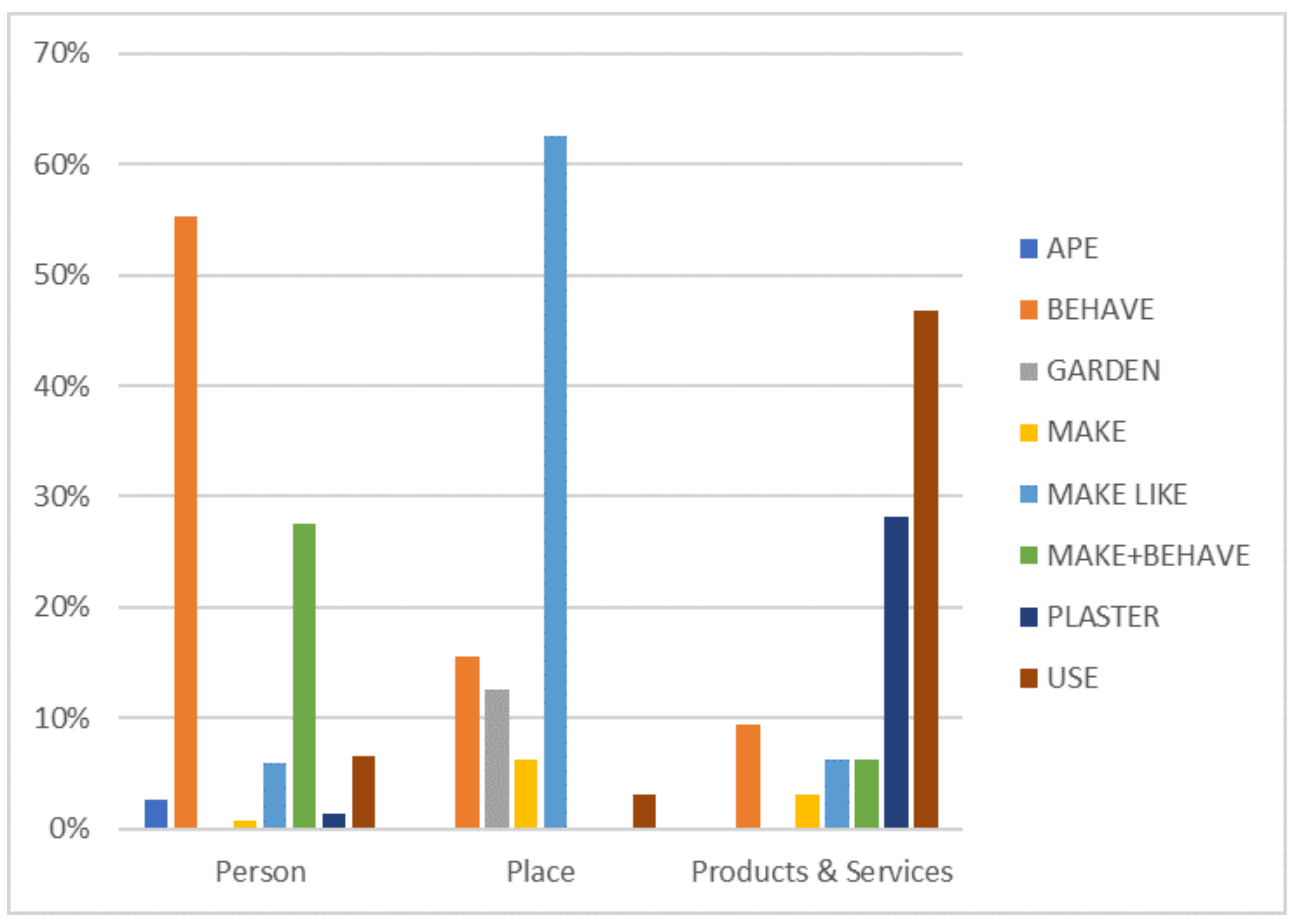

\subsubsection{Products \& Services PN (P\&S PN)}

P\&S PNs seem to be linked to two patterns: USE and PLASTER, respectively representing $47 \%$ and $28 \%$ of the category. There are also minor semantic behaviours linked to this type of PN, namely BEHAVE (9\%), MAKE LIKE (6\%), MAKE+BEHAVE (6\%) and MAKE (3\%). The reason for the link between PLASTER and USE and P\&S PN seems quite straightforward: both families involve a metonymy whose base is an object, respectively OBJECT INVOLVED FOR ACTION (as for Astroturf, Section 2.2.3.) and INSTRUMENT FOR ACTION (as for hoover: “To clean with a Hoover" ['Hoover, n.' 1989]). The nature of a P\&S PN also implies a reference to an object, which makes this relation easily understandable. Even in the case of a service, as in photomaton ("To photograph in a photo booth" ['photomaton, v.' 2006]), there is a reference to the object which makes the service possible, and this object is at the basis of the semantic behaviour, in this case USE. The minor families which can be observed with P\&S PNs need specific explanations. For MAKE, the reason is the same, as this family is linked to the metonymy RESULT OBJECT FOR ACTION (as in Penguin).

MAKE+BEHAVE can be observed in the case of services referring to a process (as in magnaflux: "To test using the magnaflux method" ['magnaflux, v.' 2000]). As such, they are comparable to immaterial inventions made by scientists and it is no surprise that they would be impacted by the metonymy PROCESS FOR ACTION.

The situation is a little more complicated for MAKE LIKE which is observed in bovrilize ("To concentrate the essence of" ['bovrilize, v.' 1989]) and McDonaldize (see Section 2.2.3. for the definition). In the first case, the PN refers to an object defined as "a concentrated essence of beef" ['Bovril, n.' 1989]. In order to obtain the MAKE LIKE semantic behaviour, the metonymy CATEGORY FOR DEFINING PROPERTY selects the manufacturing process of the object as a salient property. As a result, the verbal 
metonymy PROPERTY FOR RESULT OF ACTION is possible. In order to shift from the meaning denoting the result of the process on an object to its result on an abstract entity, the cognitive process of generalization ${ }^{28}$ needs to be hypothesized so that the semantics of the verb can also apply to abstract things as illustrated in the OED quote below:

(6) His fondness for bovrilising thought into so small a compass of words that the sentences are really too 'meaty' ['Bovrilize, v.' 1989]. consists of a PN whose reference is a newspaper (Observator: "To be mentioned in The Observator" [2004], North-Britonize: "To publish in The North Briton" [2003]). The semantic relationship between $\mathrm{V}$ and $\mathrm{PN}$ is useful here to understand what is at stake in these derivations (see Section 2.2.2.). Indeed, the GARDEN relationship (different from the GARDEN family) suggests that these entries fall under the analysis for Place PN (see Section 3.3.2.). The second case is illustrated by the entry Shake ' $n$ Bake ("To treat (a person) in a manner related in some way to the product Shake 'n Bake, esp. with reference to speed or manipulation" [2003]), whose PN etymon refers to "a powdered seasoning in which meat, etc., may be coated prior to baking by being shaken in a bag supplied for the purpose" ['Shake 'n Bake, n. and Adj.' 2003]. In this instance of derivation, the metonymy CATEGORY FOR DEFINING PROPERTY selects from the PN the human behaviour associated with the use of this product. As a result, the category of the lexeme switches to human behaviour and falls under the analysis of Person PN within the BEHAVE family (see Section 3.3.3.). The previous explanations show that two prototypical behaviours are linked to a P\&S PN etymon, namely USE and PLASTER, while minor families involve the presence of more complex processes to reach the derived meaning.

\subsubsection{Place $P N$}

Place PN is largely dominated by the MAKE LIKE semantic behaviour (63\% of Place PN). The GARDEN family, even though it only occupies the third place in this category (13\%), seems to be specific to this type of PN, as is shown by its absence from the other types. The other families also represented in Place PN are: BEHAVE (16\%), MAKE (6\%) and USE (3\%). As I mentioned in Section 2.2.2., the MAKE LIKE relationship is a type of MAKE relationship with the main difference that the creation-event of the MAKE LIKE relationship denotes a resemblance to a referent and not the actual duplication of the referent. The nature of proper names as unique referents for unique entities makes the use of the MAKE relationship problematic, and the use of MAKE LIKE more likely. There is a direct link between the MAKE LIKE relationship and the MAKE LIKE family which lies in the verbal metonymy PROPERTY FOR RESULT OF ACTION. The notion of 'result' involves a process of creation, so does the notion 'make'. The main question lies in the correlation between Place PN and MAKE LIKE. The hypothesis is that locations can be human-made and consequently can be reproduced elsewhere. The assumption goes further, however, as not only the material features of a place can be copied (as 
illustrated in Birminghamize), but also the general characteristics of the people who live in this place (as in Americanize).

The GARDEN family involves the verbal metonymy EVENT FOR ACTION (as in Pearl Harbour). This metonymy is compatible with Place-PNs because an event does not only occur at a certain time, but also at a certain place, so an event is partly defined by its spatial nature. The explanation for the BEHAVE family in this type of PN also derives from the definition of a location. Indeed, a city like Porto is defined not only by its streets, buildings, and so on, but also by its inhabitants. As a result, the metonymy CATEGORY FOR DEFINING PROPERTY can select a type of behaviour typical of a place and lead to the creation of the BEHAVE meaning. The main difference between a BEHAVE semantic pattern connected to a Place PN and one connected to a Person PN can be summarized in the dichotomy collective/typical behaviour (Place PN) vs. idiosyncratic behaviour (Person PN) ${ }^{29}$. For USE and MAKE, the explanation is also related: if a place is known for the production of a typical object, the object can be selected for the verbal metonymy, explaining the existence of USE (as in hackney) and MAKE (as in morocco) for this type of $\mathrm{PN}^{30}$.

\subsubsection{Person PN}

Finally, Person PN seems to be the type which allows the most variety in semantic patterns as only GARDEN is not included. However, the patterns which seem to be most likely associated with a Person PN verb are BEHAVE (55\%) and MAKE+BEHAVE (28\%). The APE family is considered to be a specific case of BEHAVE. The minor behaviours for this type of PN are as follows: USE (7\%), MAKE LIKE (6\%), PLASTER (1\%) and MAKE (1\%). The connection between the BEHAVE family and Person PN is quite straightforward as a type of behaviour can easily be selected from a person (as in bogart ${ }^{31}$ ). For MAKE+BEHAVE, the link is licensed by the metonymy CREATOR FOR CREATION, which selects a process considered to be originally developed by the person, or deeply linked to this person. This process can be a method (as in macadamize) or a doctrine (as in Mithraize $^{32}$ ). In both cases, the creation is abstract.

When the creation selected through the metonymy CREATOR FOR CREATION is concrete, then the semantic behaviour is of the USE type (as in Mauser). The PLASTER family is expected to follow a similar reasoning, however, the two instances of this type of semantic behaviour (Oscar and tommy) do not show the CREATOR FOR CREATION metonymy. In both cases, the OBJECT INVOLVED FOR ACTION metonymy is made possible by the metaphor A THING IS A PERSON which is the process of personification of an object. The absence of step 1 metonymy in these two cases can be explained by the lack of direct link between the PN and the verb meaning: in the case of Oscar ("To award an Oscar to (a person or film)" [2004]), the connection between the referent of the PN - someone's uncle who vaguely resembled the statue - and the meaning of the verb is far apart, and in the case of tommy ("To subject (a worker) to the tommy or truck system" [2018]), the PN is generic and does not have a specified referent. The MAKE family, which represents only one instance (Rumfordize), only differs from USE in the verbal metonymy RESULT OBJECT FOR ACTION. Lastly, the MAKE LIKE family is compatible with the Person PN when the property selected from the Person PN can be copied onto someone / something, as illustrated in $(7)^{33}$ : 
(7) The evangelist in motley who duncifies the Spirit to accommodate the public ['Duncify, v.' 2018]

71 To summarize, the analysis suggests that typically the BEHAVE and MAKE+BEHAVE semantic families are connected to Person PNs, the MAKE LIKE ${ }^{34}$ and GARDEN families are connected to Place PNs, and the USE and PLASTER families are connected to P\&S PNs. The possibility for different types of PN to be compatible with some (but not all) of the semantics families lies in their inherent semantics: a Person PN can become, through metonymic processes, a behaviour, an abstract or concrete object, but, according to the data, not an event ${ }^{35}$; a Place PN can become a behaviour, an event, or a concrete object, but not an abstract object; and a P\&S PN can become a behaviour, an abstract or concrete object, but not an event.

\subsection{The evolution of meaning through time}

Figure 5 shows the five main semantic families of the data and their evolution through time. ${ }^{36}$

Figure 5. Main semantic families through time

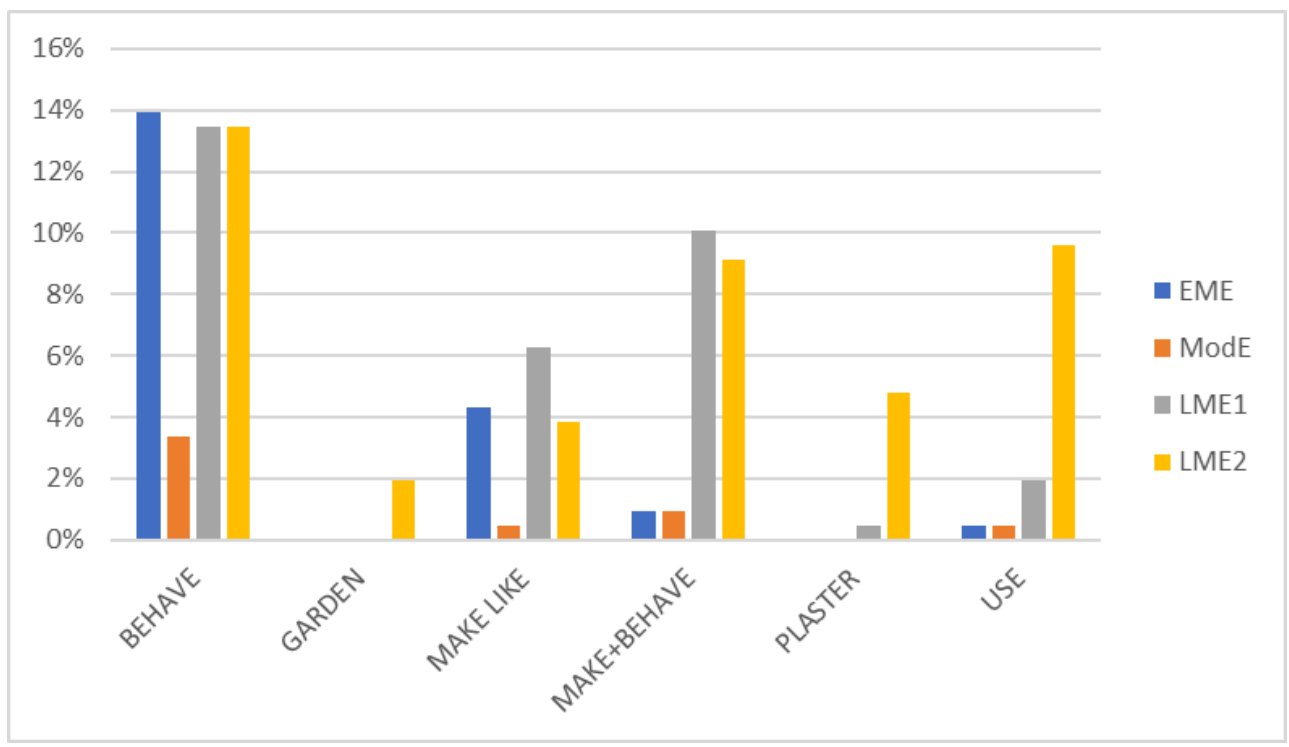

Once again, the data for the ModE period need to be put aside as the discrepancy mostly visible for the BEHAVE family - with the other periods may not reflect a linguistic reality but most likely a lack of data. The strong stability of the BEHAVE family through the whole period is striking. As mentioned in Section 3.3.3., the BEHAVE family is usually linked to Person-PNs. As a result, the stability of the semantic family is simply linked to its connection to human behaviour. To a lesser extent, the situation is the same for the MAKE LIKE family which is - in the data - linked to Place-PNs. This stability is most likely linked to the stable nature of a location. By contrast, the MAKE+BEHAVE family, which is also connected to Person-PNs, shows a spectacular increase from LME1 onwards. As observed in Section 3.3.3., this family is linked to abstract objects such as discoveries and inventions. The stronger place that sciences and scientists have taken since the $19^{\text {th }}$ century may partly explain this increase. 
74 Finally, the PLASTER and USE families are almost non-existent before the LME2 period with a slow beginning during the LME1 period. As these two families are mostly linked to $\mathrm{P} \& S$ PN, this late increase parallels the late apparition of P\&S PN as verbs (see Figure 2, Section 3.1.). This increase is probably linked to the globalization of the economy during the $20^{\text {th }}$ century coupled with the standardization of consumption. In other words, as companies globalize and offer their services nationwide and worldwide, the consumers share more and more practices with other people as they use the same brands and products in their everyday lives.

\section{Predictive model}

The previous section has unveiled two features for this type of denominal verb. First, the diachronic approach to verbs originating from proper names is relevant insofar as it shows (1) the relative stability of the process through time, and (2) the impact of society on language. As a result, a predictive model can be drawn from the present data but with two major limits to keep in mind: (i) this model will be a reflection of the current world, and (ii) the limited nature of the data means that the following model would benefit from a wider set of data including slang verbs and ephemeral neologisms.

The first limit is linked to the observation that if a similar study had taken place during the LME1 period, for instance, it would have probably ignored the existence of P\&S-PN and the USE and PLASTER semantic families whose development, as far as PNs are concerned, parallels the globalization of economy. Hence, other semantic families may emerge for verbs originating from PN that we cannot predict yet.

Secondly, the data presented in the previous sections have shown that metonymy is at the heart of this type of derivation regardless of the morphology of the output. As mentioned in Section 1.3., Kövecses \& Radden [1998] do not take any specific position on the debate surrounding the metonymic nature of form-changing word-formation processes. However, when a speaker uses a PN as a verb - before the lexeme is institutionalized - they choose one morphology over the others. If the link between conversion and metonymy is quite settled among researchers, there is no reason why the same cognitive process would not apply when the morphology selected is the result of suffixation, for example. This is possible because metonymy is a cognitive process which is so "entrenched and pervasive, they provide speakers with natural "cognitive links" that enable them to move from one entity (the vehicle) to another (the target) without any effort or even subconsciously" [Kövecses \& Radden 1998: 61] ${ }^{37}$.

The observations made in Section 3 show that there are correlations between the type of PN and the semantics of the derived verbs. The following models are based on the assumption that these correlations are cause-consequence relations. As a result, the model will be presented through three sub-models for each type of PN.

\subsection{Person-PN}

79 As mentioned earlier, the main type of PN represented in the data is the Person PN type (71\%). From this figure, the following predictive assumption can be inferred: PersonPNs are the most likely to generate a derived verb. This observation seems to be directly linked to the nature and distribution of PNs in the real world. Indeed, as there 
are more persons than places (which bear a name), then there are more Person PNs than Place PNs. The same reasoning explains the inferior number of P\&S PNs compared to Person PNs.

\subsubsection{Main patterns}

As described in Section 3.3.3., two semantic behaviours stand out for the Person PN type, namely BEHAVE and MAKE+BEHAVE. The presentation of these two semantic families as the main patterns of Person-PN verbal derivations is only based on the present data. It is possible that other patterns could emerge (such as USE or MAKE LIKE) if a bigger set was analysed. Furthermore, this study only considers the first definition for each verb. An analysis of the cases of polysemy could also lead to the emergence of secondary patterns. However, these two families are likely to remain relevant ${ }^{38}$.

The predictive model for Person PN is presented in the Figure 6:

Figure 6. Person-PN semantic model

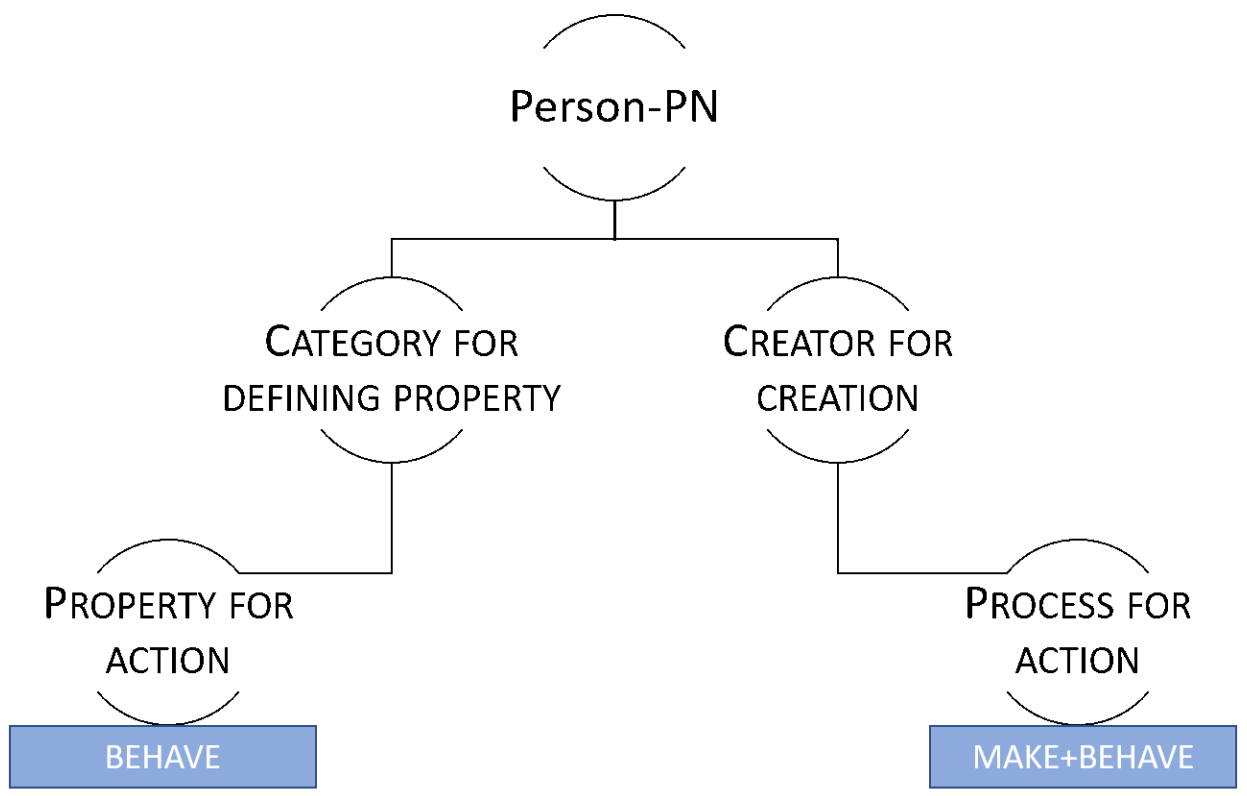

The BEHAVE family, which represents more than half of the verbs originating from a Person-PN, is by far the most likely pattern. Figure 6 does not show morphological processes, nor does it include intermediate cognitive processes which may happen before the CATEGORY FOR DEFINING PROPERTY metonymy. However, the data only includes three instances of intermediate processes in this category, they are described in the following examples:

(8) CREATOR FOR CREATION (zeppelin)

(9) POSSESSOR FOR POSSESSED (maverick: “To seize or brand (an unbranded calf) as one's own" [2001])

(10) A HOMOSEXUAL MAN IS A WOMAN (molly: "To engage in homosexual anal intercourse with" ['molly, $\mathrm{v}^{1}$ '2002]) ${ }^{39}$ 
83

cases suggest two things: (i) intermediate cognitive processes are possible and impact the selection of the property which leads to the verbal meaning; (ii) most verbs follow the same two-step process which seems to be the most typical semantic structure for verbal derivation from PN. The MAKE+BEHAVE family confirms (ii) even more strikingly as no intermediate process is included in the present data. From a diachronic perspective, the most likely semantics of verbs originating from Person-PN before LME1 is the BEHAVE type.

\subsubsection{Minor patterns and oddities}

alysis provided in Section 3.3. gave explanations for the existence of minor processes in the Person-PN paradigm. When a verb is created from a Person-PN, the data shows that not only a behaviour or process (abstract object) can be selected, but also a concrete object created by the PN. This observation allows for the existence of the USE, PLASTER and MAKE behaviours. When a concrete object is selected from a Person-PN, then I argue that it behaves like a P\&S-PN. The situation is different for the MAKE LIKE behaviour. Indeed, there is no intrinsic connection between this semantic pattern and a Place-PN apart from their compatibility. The fact that MAKE LIKE is considered a typical pattern for Place-PN is based on the present data. However, it appears that this pattern is also compatible with a Person-PN although it does not seem to be as productive as the main patterns described above. However, a preliminary linguistic survey presented in Héois [2020] and based solely on Person-PN in American English suggests that the MAKE LIKE family for Person-PN may be underrepresented in the present study.

The main oddities in the Person-PN paradigm are linked to what was labelled as APE. From a pragmatic point of view, its existence is quite surprising: the full set of characteristics of the Person-PN are selected, and it leads to a situation in which only one metonymy is involved, namely AGENT FOR ACTION. In the real world, that a person would behave exactly in the same way as another person is unlikely except in the specific domain of acting. This explanation may be right for Poor-Robin as its definition suggests:

(11) 'Poor-Robin, v.': "to play the part of Poor Robin" [2006].

The definition includes vocabulary from the semantic field of theatre (underlined section). For the other three instances of APE, the explanation may lie on the lack of specificity of the definitions, as illustrated below:

(12) 'Frederize, v.': “to take the part of Emperor Frederick” [1989].

(13) 'Quixote, v.' ('Quixotize, v.'): “to behave like Don Quixote” [2008].

The lack of details in these definitions is probably linked to the lack of available data for these lexemes which are now obsolete. Hence, the meaning, which is usually inferred from several occurrences, may have been hard to specify. If the definitions were more specific, I suggest that they could be categorized in the BEHAVE family and would follow the process described in Figure 6. 


\subsection{Place-PN}

\subsubsection{Main patterns}

There are fewer instances of Place-PN in the data: 33 against 160 for the Person-PN type. Contrary to persons and products \& services, places tend to exist with a stable name for a long period of time. In Section 3.3.2., I observed two semantic patterns which appear to be more likely associated with a Place-PN. MAKE LIKE counts for more than half of the examples in this category, despite its absence of intrinsic link with Place-PN. GARDEN does not appear in any other category, which suggests that its use is constrained to specific types of etymons, in our case Place-PNs. Figure 7 presents the model for this category of PN. According to the data, however, the MAKE LIKE semantic behaviour is the most likely to be associated with a Place-PN.

Figure 7. Place-PN semantic model

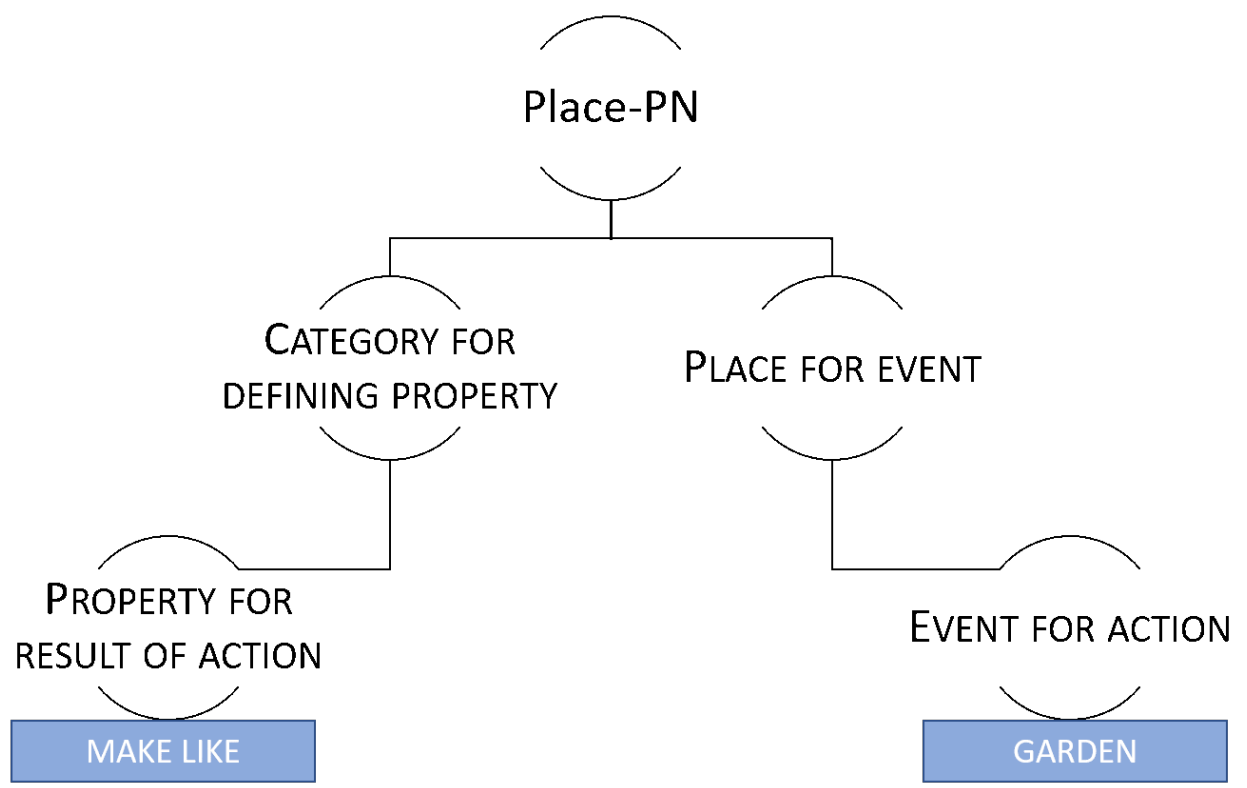

As was the case for the BEHAVE family, possible intermediate processes can take place in the MAKE LIKE family before the CATEGORY FOR DEFINING PROPERTY metonymy. They are more numerous both in number and in proportion, but they can be summarized into only two different patterns as (12) and (13) demonstrate:

(14) PLACE FOR INHABITANTS/SOCIETY (Americanize, Arabianize, etc.)

(15) PLACE FOR INSTITUTION (Genevate ${ }^{40}$ )

The fact that (15) only displays one instance tends to suggest that (14) is a more productive intermediate process. The GARDEN family, on the other hand, does not include any intermediate process as far as the present data is concerned.

\subsubsection{Minor patterns}

91

In Section 3.3.2., I described the minor patterns of the Place-PN type, namely: BEHAVE, MAKE and USE. The last two families are compatible with this type of PN when a 
concrete object is available for selection because of its direct connection with the place. The BEHAVE type, which accounts for almost a fifth of the category is linked to the fact that a place can be filled with people. When a behaviour is connected to a specific place (like drinking Porto wine), then this collective behaviour can be selected for the derived verb.

\subsection{Products \& Services-PN}

\subsubsection{Main patterns}

To conclude this presentation on the predictive semantic model, I will now present the result of the analysis for the P\&S-PN type. With almost half of its instances, this type is by far dominated by the USE family. The second relevant pattern is PLASTER with around a third of the entries. Considering the number of instances of P\&S-PN in the data (32), the same caution must be kept in mind as for Place-PNs. Figure 8 presents the potential predictive model for this category.

Figure 8. P\&S-PN semantic model

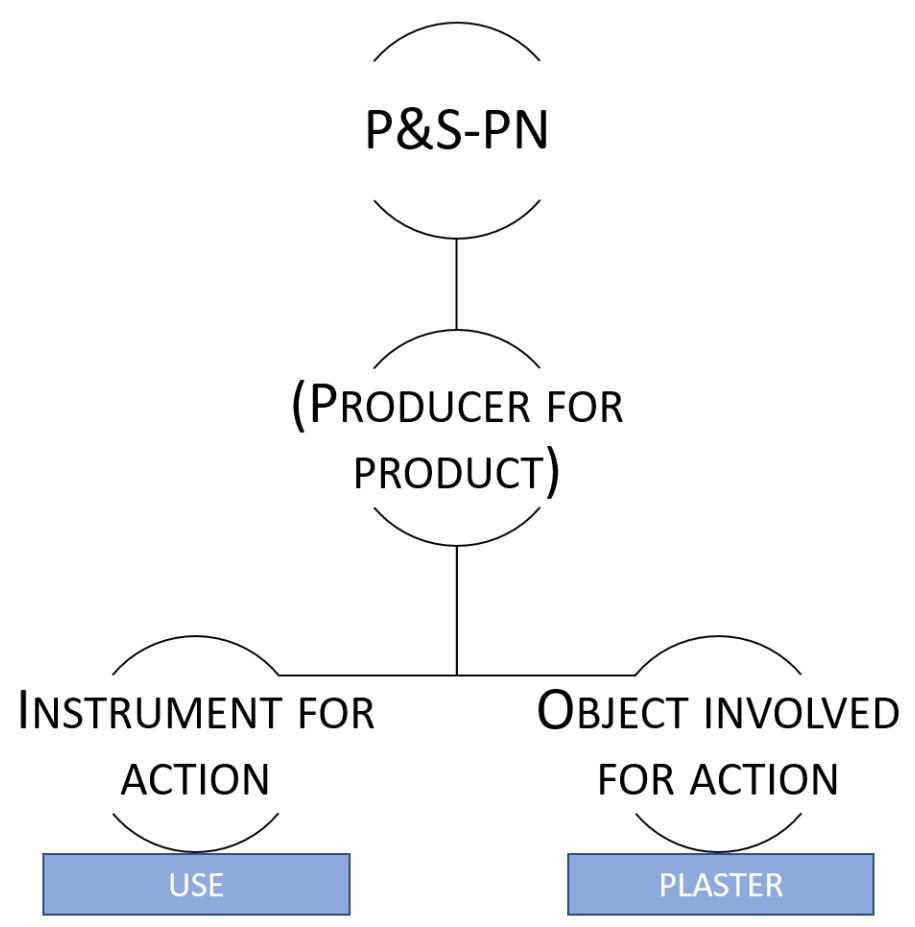

Contrary to the previous PNs, there are no attested uses of intermediary processes here. Moreover, the metonymy PRODUCER FOR PRODUCT is only valid if the P\&S-PN refers to the company which made the product. In many cases, as the product or service bears the same name as the company which created it, it is hard to decide whether this metonymy is involved. Considering the absence of the first step in case the name of the product is the verb etymon, and considering the fact that all previous processes included at least two steps between the proper name and the verb, the model in Figure 8 suggests that a proprietary name (the name of a product) does not behave like a proper name regarding verbal derivation. On the other hand, if the name of the company is the etymon of the verb, then the first metonymy applies, and the PN-to-V 
two-step semantic structure is kept. The observation that a proprietary name does not behave like a PN (semantically) suggests that it is not a PN. The definition of a PN as referring to a single referent would lead to a similar conclusion. However, other elements, such as syntax, may result in the categorization of proprietary names as PNs because they may not behave like common nouns either, as illustrated in the examples below:

(16) to use Facebook

(17) *a Facebook

(18) *a piece of Facebook

In (16), Facebook clearly refers to the product, not the company: the proprietary name is used. If it behaved like a common noun, then Facebook would be either countable (17) or uncountable (18). This issue goes beyond the scope of this article. The status of proprietary names is however problematic. One proposition could consist in the assumption of a continuum from common nouns to proper names, but further research would be needed to answer this question.

\subsubsection{Minor patterns and oddities}

The minor patterns for the P\&S-PN type, as described in Section 3.3.1., are as follows: BEHAVE, MAKE LIKE, MAKE+BEHAVE, and MAKE. It may be surprising that the MAKE family, which is intrinsically linked to a concrete object (just like USE and PLASTER), does not stand out in this category. Indeed, the compatibility of MAKE with a P\&S PN is linked to the fact that a concrete object is selected, but its rarity (only one occurrence) suggests that this semantic behaviour is not likely. This lack of productivity may be linked to the nature of proprietary names. As they are the legal property of a company or a person, it is legally problematic to create a replica of the product. As a result, unless a proprietary name becomes known to refer to a type of object, and not only a specific object within the category, then the MAKE behaviour is not expected. The MAKE LIKE and BEHAVE families are compatible with a P\&S-PN when a feature of the product or a feature connected to the product can be selected, as illustrated in Shake' $n$ Bake ("To treat (a person) in a manner related in some way to the product Shake ' $n$ Bake, esp. with reference to speed or manipulation" [2003]). In this example, the CATEGORY FOR DEFINING PROPERTY metonymy selects a behavioural feature associated with the use of this product, in this case speed or manipulation, and is combined to the metaphor A PERSON IS AN OBJECT, and thus explains the BEHAVE family. The MAKE+BEHAVE family appears to only be connected with services referring to methods or processes. As such, these P\&S are very similar to abstract inventions of individuals, and consequently behave in the same way.

In a nutshell, the data under scrutiny led to three predictive sub-models according to each PN-type. These models can be summarized through four conclusions:

- The most likely PN to be derived as a verb is a Person-PN;

- Person PN verbs will most likely select a BEHAVE meaning or a MAKE+BEHAVE meaning;

- Place PN verbs are most likely to present a MAKE LIKE semantic pattern, or alternatively a GARDEN behaviour;

- Products \& Services PN verbs will usually convey a USE type of meaning, or alternatively a PLASTER behaviour. 
models suggest that the semantic pattern of a verb originating from a PN can, in most cases, be predicted by the PN-etymon. The criteria which motivate, for each PN, the selection of one semantic pattern or the other are not investigated in the present study. A finer analysis of the semantics of the proper names would be needed in order to propose an explanation. However, as is shown by the MAKE+BEHAVE family which usually entails a Person-PN within the science field, what allows for a semantic pattern to be selected is linked to salience and shared knowledge.

\section{Conclusion}

Like proper names which are both linguistic and cultural items, verbs originating from proper names are deeply influenced by the society and culture in which they are coined. As a result, they are a window to a culture at a certain time. Considering the limited number of data, the present study is not sufficient to present any definite conclusions on this matter which would benefit from a corpus linguistics approach. However, the fast increase in the use of P\&S PNs as verbs in the $20^{\text {th }}$ century suggests that this linguistic reality is linked to the increasing standardization of consumption. Similarly, the appearance of the MAKE+BEHAVE family around the $19^{\text {th }}$ century is an indication of the place sciences began to take in the English-speaking world as a consequence of the Enlightenment and the Industrial Revolution.

The present analysis also suggests that verbal derivation from a proper name is structurally stable through time and metonymic in nature regardless of the morphology of the derived verb. Considering this last observation as well as the fact that -ize suffixation and conversion can be found for the same types of meanings, the present study questions the extent to which a suffix such as -ize can be considered to have a meaning. The analysis suggests that the interaction between the suffix and the meaning is one of compatibility, and that the semantics is mostly built through metonymic processes. Moreover, verbal derivation from proper names involves a twostep cognitive process which requires at least two metonymies, including a mandatory verbal metonymy. In marginal cases, the non-verbal metonymy can be replaced by a metaphor. This finding suggests that proprietary names, in terms of their derivational behaviour, cannot be fully considered proper names. I am currently working on generalizing this approach to all denominal verbs in order to refine those hypotheses.

\section{BIBLIOGRAPHY}

ALGEO John, 1998, "Vocabulary", in ROMAINE Suzanne (Ed.), The Cambridge History of the English Language. Volume 4: 1776-1997, Cambridge: Cambridge University Press, 57-91.

BRDAR Mario \& BRDAR-SZABO Rita, 2013, "Some Reflections on Metonymy and Word-Formation", ExELL, Volume 1, n 1, 40-62.

Lexis, 16 | 2020 
CLARK Eve V. \& CLARK Herbert H., 1979, “When Nouns Surface as Verbs”, Language, Volume 55, n4, 767-811.

DIXON Robert M. W., 2008, “Deriving Verbs in English”, Language Sciences, Volume 30, n 1, 31-52. DONNELLAN Keith, 1972, "Proper Names and Identifying Descriptions”, in DAVIDSON David \& HARMAN Gilbert (Eds.), Semantics of Natural Language, $2^{\text {nd }}$ Ed., Dordrecht \& Boston: Reidel, 356-379.

DONNELLAN Keith, 1974, “Speaking of Nothing”, The Philosophical Review, n83, 3-31.

EVANS Vyvyan \& GREEN Melanie, 2006, Cognitive Linguistics: An Introduction, Edinburgh: Edinburgh University Press.

GARY-PRIEUR Marie-Noëlle, 2016, « Le nom propre comme catégorie de la grammaire », Langue française, Volume 190, n² 2, 45-64.

GRADDOL David, LEITH Dick, sWANN Joan, RHYS Martin \& GILLEN Julia, 2007, Changing English, London: Routledge.

HÉOIS Aurélie, 2020, From Proper Names to Verbs in English: A Corpus-Based Morpho-Semantic Study of Verbs Originating from Proper Names [Unpublished MA thesis], Jean Moulin University Lyon 3.

HUDDLESTON Rodney D. \& PAYNE John, 2002, "Nouns and Noun Phrases", The Cambridge Grammar of the English Language, Cambridge: Cambridge University Press, 323-523.

HUGUIN Mathilde, 2018, « Noms de personnalités politiques et construction morphologique. Pourquoi les macroniens peuvent-ils souffrir de macronite mais aucun jacklanguien ne souffre de jacklanguite ?» [communication], 17e Séminaire-apéro du CEL, Lyon, disponible à http:// cel.univ-lyon3.fr/seminaire-diffusion-du-17e-seminaire-apero-du-cel-du-30novembre-2018-1197339.kjsp.

JANDA Laura A., 2011, "Metonymy in Word-Formation”, Cognitive Linguistics, Volume 22, $\mathrm{n}^{\circ} 2$, 359-392.

JESPERSEN Otto, 1924, The Philosophy of Grammar, Chicago \& London: The University of Chicago Press.

KÖVECSES Zoltan \& RADDEN Gunter, 1998, "Metonymy: Developing a Cognitive Linguistic View”, Cognitive Linguistics, Volume $9, \mathrm{n}^{\circ} 1,37-77$.

KRIPKE Saul, 1972, "Naming and Necessity”, in DAVIDSON David \& HARMAN Gilbert (Eds.), Semantics of Natural Language, $2^{\text {nd }}$ Ed., Dordrecht \& Boston: Reidel, 253-355.

KURYŁOWICZ Jerzy, 1980, “The Linguistic Status of Proper Nouns (Names)”, Onomastica, n²5, 5-8.

LAKOFF George, 1987, Women, Fire, and Dangerous Things: What Categories Reveal about the Mind, Chicago: University of Chicago Press.

LASS Roger (Ed.), 1999, The Cambridge History of the English Language. Volume 3: 1476-1776, Cambridge: Cambridge University Press.

LIEBER Rochelle, 2004, Morphology and Lexical Semantics, Cambridge: Cambridge University Press.

LIPKA Leonhard, 1992, "Lexicalization and Institutionalization in English and German", Universitätsbibliothek Der Ludwig-Maximilians-Universität München, $\mathrm{n}^{\circ}$ 1, 1-13.

MCCLURE Peter, 2012, "Personal Names and the Development of English", Oxford English Dictionary online, available at https://public.oed.com/blog/personal-names-and-the-development-ofenglish/. 
MILL John Stuart, 1882, "Of Names and Propositions", in A System of Logic, Ratiocinative and Inductive, $8^{\text {th }}$ Ed., New York: Harper \& Brothers, 26-121.

NEVALAINEN Terttu, 1999, “Early Modern English Lexis and Semantics”, in Lass Roger (Ed.), The Cambridge History of the English Language. Volume 3: 1476-1776, Cambridge: Cambridge University Press, 332-458.

NYSTRÖM Staffan, 2016, "Names and Meaning”, in HOUGH Carole (Ed.), The Oxford Handbook of Names and Naming, Oxford: Oxford University Press, 39-51.

OED, 2018a, “About”, Oxford English Dictionary, available at http://public.oed.com/about/.

OED, 2018b, "Sorting of Quotations", Oxford English Dictionary, available at http://public.oed.com/ history/rewriting-the-oed/sorting-of-quotations/.

PANTHER Klaus-Uwe \& THORNBURG Linda L., 2007, “Metonymy”, in GEERAERTS Dirk \& CUYCKENS Hubert (Eds.), The Oxford Handbook of Cognitive Linguistics, Oxford: Oxford University Press: 236-263.

PLAG Ingo, 1999, Morphological Productivity: Structural Constraints in English Derivation, Berlin \& New York: Mouton de Gruyter.

PLAG Ingo, 2003, Word-Formation in English, Cambridge: Cambridge University Press.

ROMAINE Suzanne (Ed.), 1998, The Cambridge History of the English Language. Volume 4: 1776-1997, Cambridge: Cambridge University Press.

ŠTEKAUER Pavol, 1997, "On the Semiotics of Proper Names and Their Conversion", AAA: Arbeiten Aus Anglistik Und Amerikanistik, Volume 22, $\mathrm{n}^{\circ} 1,27-36$.

TOURNIER Jean, 2007 (1985), Introduction Descriptive à la Lexicogénétique de l'Anglais Contemporain, Genève : Slatkine Érudition.

VALERA Salvador, 2014, “Conversion”, in LIEBER Rochelle \& ŠTEKAUER Pavol (Eds.), The Oxford Handbook of Derivational Morphology, Oxford: Oxford University Press, 154-168.

VAXELAIRE Jean-Louis, 2016, « De la définition linguistique du nom propre », Langue Française, Volume $190, n^{\circ} 2,65-78$.

\section{Corpus and dictionaries}

Oxford English Dictionary [Online], 2020, Oxford University Press, available with subscription at www.oed.com.

[The Guardian 2020] sUNKARA Bhaskar, 2020, "Brace Yourselves. The next Donald Trump Could Be Much Worse", The Guardian, 10 November 2020, available at: http://www.theguardian.com/ commentisfree/2020/nov/10/biden-establishment-democrat-next-donald-trump, consulted on 23 November 2020.

\section{NOTES}

1. "The proper name is not a linguistic sign, only a label, it has no meaning when the referent is unknown, and it gains more semantic weight, the more we learn about this referent", my translation.

2. The term conversion is used out of convenience with no attempt to take position in the debate about this word-formation process. Moreover, in the present study, conversion is considered a derivation process. As a result, the term derivation will usually include both suffixation and conversion, unless stated otherwise. 
3. In Table 1 , relationship types and hypernyms preceded by $\left(^{*}\right)$ are not by Tournier. I defined them based on his typology and descriptions.

4. Kövecses \& Radden [1998: 42-46] define three types of metonymy: sign, reference, and concept. The present study focuses on concept metonymies which connect entities within the same ontological realm.

5. In this study, I only took into account the first and earliest definition for each entry. The study of all the definitions is currently under way.

6. All the definitions are quoted from the Oxford English Dictionary online. Each verb definition is provided when relevant to the analysis.

7. The alternative is to consider that in the case of Pasteur the meaning is built through a metonymic process (or chain) of the type CREATOR FOR CREATION > PROCESS FOR ACTION (in which the creation is a scientific method or process), while the meaning of pasteurize is built through a process of suffixation in which the -ize suffix is assumed to carry the same meaning as the metonymy.

8. My current research on denominal verbs also includes verbs from slang dictionaries. I would like to thank one of the anonymous reviewers for the recommendation.

9. A recent exploration of the $O E D$ for my current research on denominal verbs has shown that the keyword set "the name of" would have also yielded some results.

10. In this article, the use of capitalized letters for verbs transcribes the OED information. In cases where both spellings are attested, the entry 'orthography' is used.

11. In the $O E D$, the first definition is also the first recorded meaning of a lexeme.

12. For lack of a better terminology, Huguin's categories were simply anglicized even though some of the terms are not recorded in standard English dictionaries.

13. Mafeking (now Mafikeng), South Africa.

14. The added categories are marked with $\left(^{*}\right)$.

15. All the definitions are extracted from the OED online.

16. Unknown referent refers to proper names which do not refer to a specific entity, as a result, they encompass generic names. The relationship between the PN and the verb cannot be defined with the same methodology as the other instances of the data set. As their semantic behavior is however similar to some other cases, they are categorized in Section 2.2.3.

17. In this specific case, the second definition of the entry is considered as the first one refers to a "jacklight" which complicates the matter further. This entry is even more problematic as most definitions do not seem to share a semantic link. Further research is needed in order to decide whether all these definitions are linked by polysemy of homonymy.

18. "Practically any kind of relations is possible, some of them are complex (but are sometimes related to one of the major types)", my translation.

19. The terminology used for semantic relationships in this study - and based on Tournier [2007] - is not always consistent as an anonymous evaluator pointed out. Some relationship labels are primitive predicates (such as MAKE, BEHAVE, or USE) while others are examples of the relationship (such as GARDEN, PITY, or PLASTER). They have to be understood as useful labels for semantic relationships.

20. Only back-clipping is mentioned as the data under scrutiny does not include other cases of clipping such as fore-clipping.

21. The term property is used in a very broad sense which would benefit from a more detailed analysis as it encompasses properties such as human behaviors and personality traits, as well as elements which can be considered as distinctive of a place or a product/service. As a result, it probably hides some strong differences between the verbs.

22. 'Rumfordize, v.': "To convert (a fireplace) into a Rumford fireplace" [2011].

23. 'McDonaldize, v.': “To make (something) resemble the McDonald's restaurant chain or its food" [2001]. 
24. 'Nestorize, v.': “To fill (a person) with the idea of being as wise as Nestor" [2003].

25. 'Oscar, v.': “To award an Oscar to (a person or film)” [2004].

26. As an anonymous reviewer pointed out, this hypothesis could be tested through a comparison of verbs from PNs in historical dictionaries of other varieties of English.

27. For the sake of presentation and clarity, the percentages for each family are defined within each type of PN, and not expressed according to the grand total as in the other graphs.

28. As the scope of this study does not involve the analysis of polysemy, the notion of generalization and its impact on semantic change will not be further explored.

29. The level of modelling proposed in this study does not allow to make this difference apparent. However, if this study was to be generalized to all denominal verbs, it seems that a more specific metonymic analysis would be necessary.

30. Hypothetically, and following this reasoning, Place PN could also lead to the PLASTER behaviour. The present data does not show, however, any instance of this type.

31. 'bogart, v.': "To force, coerce; to bully, intimidate" [2005].

32. 'Mithraize, v.': "To hold, practise, or teach the doctrines of Mithraism" [2002].

33. 'Duncify, v.': “To make a dunce of; esp. to render (a person) stupid, slow-witted, or confused" [2018].

34. According to the data, MAKE LIKE is mostly linked to Place PN, however, the semantic constraints on this behaviour are not directly linked to the notion of 'location'. They primarily concern the notions of 'creation' / 'transformation' of something which takes a patient role in the construction, and the notion of 'resemblance' (there is no identity between the source and the target).

35. It is possible for an event to be related to a specific person, but in this case, I argue that we would identify this event to a behaviour linked to this event.

36. The MAKE and APE families are put aside because of their very low number of occurrences in the data (4 in both cases), but also because the APE family is considered a specific instance of the BEHAVE family, and the MAKE family has ties to the MAKE LIKE family but the latter is more relevant when dealing with PNs (see Section 3.3.2.). Conversely, the GARDEN family, despite its equally low number of occurrences (4 as well) is kept as the analysis in Section 3.3.2. showed that it is narrowly linked to Place PNs.

37. It is not within the scope of this article to provide an explanation for the reason why one morphological process is selected over another; for an analysis and model of this phenomenon regarding verbs originating from proper names, see Héois [2020].

38. The same limits need to be considered for the two other types of PN, and even to a greater extent as they include fewer instances of verbs.

39. In (8), the intermediary process is a conceptual metaphor, with the form A IS B while metonymies take the form A FOR B.

40. 'Genevate, v.': “To introduce or imitate the doctrines or practices of the Calvinist church" [2009].

\section{ABSTRACTS}

Proper names are good examples of the interaction between language and society. They are used to refer to specific and unique entities. Taking side with the thesis which states that proper 
names have a meaning, this article explores the evolution of the use of proper names as denominal verbs in English (boycott for instance) with a specific focus on how their meaning is generated. Although this study confirms to a certain extent the impact of the historical context on the use of proper names as verbs and, as a result, suggests that this type of denominal verb serves as a window to a culture and society, it mostly argues that the semantic structure underlying the use of proper names as verbs is relatively stable through time and heavily constrained by the type of proper name used which in turn defines the chain of metonymies which can operate to form the meaning of the verb.

Le nom propre est un exemple probant de l'interaction entre langue et société. Il est utilisé pour désigner une entité spécifique et unique. Faisant sienne la théorie selon laquelle les noms propres ont un sens, cet article explore l'évolution de leur utilisation comme verbes dénominaux en anglais (par exemple le verbe boycott) et notamment comment se construit leur sens. Bien que cette étude confirme dans une certaine mesure l'impact du contexte historique sur l'utilisation des noms propres comme verbes, suggérant ainsi que ce type de verbe dénominal puisse être une fenêtre sur une culture et une société, il défend surtout l'idée que la structure sémantique à la base de l'utilisation des noms propres comme verbes est relativement stable à travers le temps, et qu'elle reste fortement contrainte par le type de nom propre utilisé qui, à son tour, détermine la chaîne métonymique qui pourra s'appliquer pour former le sens du verbe.

\section{INDEX}

Keywords: denominal verb, proper name, Oxford English Dictionary, metonymy, derivation, conversion, suffixation, diachrony

Mots-clés: verbe dénominal, nom propre, Oxford English Dictionary, métonymie, dérivation, conversion, suffixation, diachronie

\section{AUTHOR}

\section{AURÉLIE HÉOIS}

University of Lyon (Jean Moulin Lyon 3) \& Centre d'Études Linguistiques - Corpus, Discours et Sociétés (EA1663)

aurelie.heois@univ-lyon3.fr 